\title{
Phosphoinositol-4,5-Bisphosphate Regulates Auditory Hair-Cell Mechanotransduction-Channel Pore Properties and Fast Adaptation
}

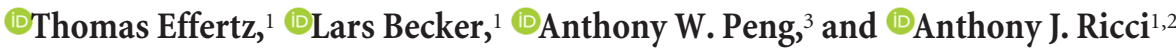 \\ ${ }^{1}$ Department of Otolaryngology, Head \& Neck Surgery, and ${ }^{2}$ Department of Molecular Cell Physiology, Stanford University, Stanford, California 94305, and \\ ${ }^{3}$ Department of Physiology and Biophysics, University of Colorado Anschutz Medical Campus, Aurora, Colorado 80045
}

Membrane proteins, such as ion channels, interact dynamically with their lipid environment. Phosphoinositol-4,5-bisphosphate ( $\left.\mathrm{PIP}_{2}\right)$ can directly or indirectly modify ion-channel properties. In auditory sensory hair cells of rats (Sprague Dawley) of either sex, PIP $_{2}$ localizes within stereocilia, near stereocilia tips. Modulating the amount of free $\mathrm{PIP}_{2}$ in inner hair-cell stereocilia resulted in the following: (1) the loss of a fast component of mechanoelectric-transduction current adaptation, (2) an increase in the number of channels open at the hair bundle's resting position, (3) a reduction of single-channel conductance, (4) a change in ion selectivity, and (5) a reduction in calcium pore blocking effects. These changes occur without altering hair-bundle compliance or the number of functional stereocilia within a given hair bundle. Although the specific molecular mechanism for PIP $_{2}$ action remains to be uncovered, data support a hypothesis for PIP ${ }_{2}$ directly regulating channel conformation to alter calcium permeation and single-channel conductance.

Key words: adaptation; cell membrane; hair cell; mechanotransduction; $\mathrm{PIP}_{2}$

\section{Significance Statement}

How forces are relayed to the auditory mechanoelectrical transduction (MET) channel remains unknown. However, researchers have surmised that lipids might be involved. Previous work on bullfrog hair cells showed an effect of phosphoinositol-4,5bisphosphate $\left(\mathrm{PIP}_{2}\right)$ depletion on MET current amplitude and adaptation, leading to the postulation of the existence of an underlying myosin-based adaptation mechanism. We find similar results in rat cochlea hair cells but extend these data to include single-channel analysis, hair-bundle mechanics, and channel-permeation properties. These additional data attribute PIP $_{2}$ effects to actions on MET-channel properties and not motor interactions. Further findings support PIP 2 's role in modulating a fast, myosin-independent, and $\mathrm{Ca}^{2+}$-independent adaptation process, validating fast adaptation's biological origin. Together this shows PIP $_{2}$ 's pivotal role in auditory MET, likely as a direct channel modulator.

\section{Introduction}

The mammalian auditory mechanoelectrical transduction (MET) channel resides at the tip of actin-filled stereocilia organized in a staircase pattern. These stereocilia constitute the hair cell's sen-

Received May 16, 2017; revised 0ct. 5, 2017; accepted 0ct. 12, 2017.

Author contributions: T.E. and A.J.R. designed research; T.E., L.B., and A.W.P. performed research; T.E., L.B., and A.W.P. analyzed data; T.E. and A.J.R. wrote the paper.

This work was supported by postdoctoral fellowship EF100/1 to T.E. for conducting research in A.J.R.'s laboratory (German Research Foundation [Deutsche Forschungsgemeinschaft] http://www.dfg.de/en/), by RO0 DC013299 from the National Institute on Deafness and Other Communication Disorders (NIDCD) to A.W.P. and by Grant R01 DC003896 from the NIDCD to A.J.R. Core Grant P30-044992 from NIDCD supports microscope core facilities and L.B. for immunohistochemical work. We thank Bifeng Pan for preliminary work done to manipulate $\mathrm{PIP}_{2}$ levels.

The authors declare no competing financial interests.

Correspondence should be addressed to Anthony J Ricci, 0HNS/Research Division Position: Professor, 300 Pasteur Drive, Edwards Building R145, Stanford, CA 94305. E-mail: aricci@stanford.edu.

DOI:10.1523/JNEUROSCI.1351-17.2017

Copyright $\odot 2017$ the authors $\quad 0270-6474 / 17 / 3711632-15 \$ 15.00 / 0$ sory organelle, the hair bundle (Hudspeth, 2005). Filamentous structures, composed of cadherin 23 and protocadherin 15, located at the stereocilia tip, termed tip links, connect stereocilia of the second and third row with their next taller neighboring stereocilium (Kazmierczak et al., 2007). Tip links convert shearing motion between stereocilia into a force at the stereocilium tip, close to the presumed MET-channel location (Pickles et al., 1984; Beurg et al., 2009). Transmission electron microscopic data suggest that the area around the lower tip-link insertion point can show membrane "tenting" and a different membrane cytoskeleton interaction than that of the shaft region of the stereocilia (Kachar et al., 2000). However, MET-channel interactions with its lipid environment have not been closely investigated in the auditory field. Theoretical arguments suggest that lipid stretch can provide the needed force to open hair-cell MET channels. However, no direct evidence exists for either a tethered or non- 
tethered channel (Kim et al., 2011; Powers et al., 2014). In general, ion channels interact with their lipid environment (Engel and Gaub, 2008; Anishkin et al., 2014), mostly driven by hydrophilic and lipophilic interactions between the lipid bilayer and protein domains (Webb et al., 1998; Bavi et al., 2016). These interactions affect voltage-sensitive channels, such as Kv1.2 (Kruse and Hille, 2013; Smith et al., 2015) or KCNQ4 (Abderemane-Ali et al., 2012; Zaydman and Cui, 2014), and also mechanosensitive channels, such as MscL (Anishkin et al., 2014; Bavi et al., 2016), MscS (Hurst et al., 2009; Malcolm et al., 2015), TRAAK1 (Patel et al., 2001; Brohawn et al., 2014), and TREK-1 (Chemin et al., 2007a). The lipid environment can affect channels indirectly through membrane curvature/tension changes (Hardie and Franze, 2012; Anishkin et al., 2014; Hille et al., 2015; Pliotas et al., 2015; Bavi et al., 2016) or directly through individual lipid-protein interactions (Suh and Hille, 2008; Hansen et al., 2011; Brohawn et al., 2014; Zaydman and Cui, 2014; Hansen, 2015). Recent data have suggested that extracellular divalent ions indirectly affect mammalian auditory MET properties through alterations in lipid packing (Peng et al., 2016). Together, these data suggest an involvement of the lipid membrane in mammalian auditory METchannel activation. In this context, we investigated the role of phosphoinositol-4,5-bisphosphate $\left(\mathrm{PIP}_{2}\right)$ in modulating $\mathrm{MET}$ responses.

$\mathrm{PIP}_{2}$ can indirectly activate channels (such as the transient receptor potential channel) due to the conversion from its cylindrical shape to the conical-shaped diacylglycerol (Hardie and Franze, 2012). While this exemplifies an indirect lipid-channel interaction, $\mathrm{PIP}_{2}$ also directly interacts with channels (Zhang et al., 2013), such as the Kir2.2 channel (Hansen et al., 2011; Lee et al., 2016). In isolated vestibular bullfrog sacculus hair cells, $\mathrm{PIP}_{2}$ depletion reduced the MET current and its associated timedependent adaptation (Hirono et al., 2004). Hirono et al. (2004) suggested that a $\mathrm{Ca}^{2+}$-driven and myosin-based adaptation process underlies these observations, supporting an indirect modulation mechanism of $\mathrm{PIP}_{2}$ on MET. In the mammalian auditory system, $\mathrm{Ca}^{2+}$ does not drive fast adaptation (Peng et al., 2013) and myosin-based adaptation plays a lesser role when stiff probes are used to stimulate the hair bundle (Nam et al., 2015). Hence, we investigated effects of reducing free $\mathrm{PIP}_{2}$ levels on the mammalian auditory inner hair cell (IHC) MET channels. Pharmacologically blocking $\mathrm{PIP}_{2}$ replenishment or directly binding and/or extracting $\mathrm{PIP}_{2}$ from the cell membrane resulted in MET-current effects similar to those described for bullfrog saccule hair cells (Hirono et al., 2004). We extend this work to the mammalian cochlea showing no change in hair-bundle compliance. We further found reductions in single-channel conductance, $\mathrm{Ca}^{2+}$ permeation, and block of the channel. These data suggest a close and possibly direct interaction of $\mathrm{PIP}_{2}$ molecules with the MET channel.

\section{Materials and Methods}

Animal protocol/preparation. Sprague Dawley rats of both sexes and from postnatal day 7 (P7) to P10 were killed by decapitation using methods approved by the Stanford University Administrative Panel on Laboratory Animal Care. Organs of Corti were dissected and placed in recording dishes as previously described (Beurg et al., 2006, 2009; Waguespack et al., 2007; Peng et al., 2013). The tissue was viewed with an analog camera (Olympus, OLZ-150) on an Olympus microscope (BX 51WI) with a water-immersion $60 \times 1.0$ numerical aperture objective (Olympus) for electrophysiological recordings and with a digital camera (QImaging, Retiga Exi) on a custom-built swept-field confocal system (Prairie Technologies) with a water-immersion $100 \times 1.0$ numerical aperture objective. After removing the tectorial membrane, special care was taken in both experimental setups to ensure that IHC bundles were oriented ver- tically, parallel to the optical pathway. The organs of Corti were perfused with external solution (see Solutions), low external $(25 \mu \mathrm{M}) \mathrm{Ca}^{2+}$ solution, or different drugs.

Solutions. Unless stated otherwise, tissue was perfused with an extracellular solution containing the following (in $\mathrm{mm}$ ): $145 \mathrm{NaCl}, 2 \mathrm{KCl}, 2$ $\mathrm{CaCl}_{2}, 1 \mathrm{MgCl}_{2}, 10$ HEPES, 6 glucose, 2 pyruvate, 2 ascorbic acid, and 2 creatine monohydrate. Low-Ca ${ }^{2+}$ external solution contained the following: $147 \mathrm{NaCl}, 2 \mathrm{KCl}, 0.025 \mathrm{CaCl}_{2}, 10$ HEPES, 6 glucose, 2 sodium pyruvate, 2 ascorbic acid, and 2 creatine monohydrate. The $\mathrm{pH}$ of external solutions was adjusted to 7.4 by addition of $\mathrm{NaOH}$ and the osmolality ranged from 304 to $308 \mathrm{mOsm}$. After adjusting osmolality, DMSO was added to a final concentration of $0.1 \%$, to ensure drug solubility when needed and for easier comparison of control and drug-treated conditions. Phenylarsine oxide (PAO; Sigma-Aldrich) and quercetin (SigmaAldrich) were dissolved in 100\% DMSO by sonicating for $30 \mathrm{~min}$ at 37 $\mathrm{kHz}$, followed by $30 \mathrm{~min}$ at $80 \mathrm{kHz}$, using the sweep setting (sonicator: Elma Ultrasonic, Elmasonic P) followed by a 1:1000 dilution with DMSOfree external solution to a final concentration of $100 \mu \mathrm{M}$ PAO and $50 \mu \mathrm{M}$ quercetin in $0.1 \%$ DMSO. For single-channel experiments, $\mathrm{NaCl}$ was reduced to 132 and $5 \mathrm{~mm}$ 1,2-bis(o-aminophenoxy)ethane- $N, N, N^{\prime}, N^{\prime}$ tetra-acetic acid (BAPTA) added to a final osmolality of 304-308 mOsm and $0.1 \%$ DMSO. Drugs and other solutions (low $\mathrm{Ca}^{2+}, 5$ mM BAPTA) were applied to the tissue using an apical perfusion pipette (Beurg et al., 2006, 2009; Peng et al., 2013) or with a picospritzer-driven puffer pipette (size, $\sim 15-20 \mu \mathrm{m}$ ) positioned $15-30 \mu \mathrm{m}$ away from the patched cell's hair bundle on the opposite side of the patch pipette.

Unless stated otherwise, the internal patch solution contained the following (in mM): $114 \mathrm{CsCl}, 10 \mathrm{HEPES}, 3.5 \mathrm{MgCl}_{2}, 2$ ascorbic acid, $5 \mathrm{ATP}$, 5 creatine phosphate, and 1 ethylene glycol-bis ( $\beta$-aminoethyl ether)$N, N, N^{\prime}, N^{\prime}$-tetra-acetic acid (EGTA). Internal solutions were adjusted to pH 7.2 with $\mathrm{CsOH}$ and the osmolality ranged from 282 to $286 \mathrm{mOsm}$. In some experiments EGTA was replaced by $1 \mathrm{~mm}$ BAPTA. Poly-L-lysine (Sigma-Aldrich; molecular weight, 30,000-70,000), a PIP $_{2}$ antibody ( $\mathrm{PIP}_{2}-\mathrm{AB}$; clone 2C11; Invitrogen), or gentamicin (Sigma-Aldrich) were added to filtered internal solution. Poly-L-lysine was used at a final concentration of $10 \mu \mathrm{g} / \mathrm{ml}$, the $\mathrm{PIP}_{2}-\mathrm{AB}$ at a 1:100 dilution, and gentamicin at $1 \mathrm{~mm}$ concentration. For $\mathrm{Ca}^{2+}$ imaging experiments, ascorbic acid was increased to $40 \mathrm{~mm}$ and $\mathrm{CsCl}$ reduced to $117 \mathrm{~mm}$. Fluo-4FF to a final concentration of $1 \mathrm{~mm}$ and Alexa 594 to a final concentration of $50 \mu \mathrm{M}$ were added. The fluorescent dye containing internal solutions were made fresh each experimental day, spin filtered, and kept in the dark until used.

Electrophysiology. Unless stated otherwise, whole-cell patch-clamp recordings were performed at room temperature $\left(19-22^{\circ} \mathrm{C}\right)$ with borosilicate patch pipettes of $2-3 \mathrm{M} \Omega$ resistance as previously described (Peng et al., 2013). MET currents were low-pass filtered at $100 \mathrm{kHz}$, measured with an Axopatch 200B patch-clamp amplifier, digitized with a daq3000 (IOtech) at $500 \mathrm{kHz}$, and recorded with jClamp (SciSoft). MET currents were off-line filtered at $10 \mathrm{kHz}$ for further visualization and analysis. For single-channel recordings, hair bundles were stimulated with a fluid jet, MET currents were low-pass filtered at $1 \mathrm{kHz}$, and the $5 \times$ gain setting of the Axopatch 200B amplifier was used. Voltages were adjusted off-line for liquid junction potential and cells were held at $-84 \mathrm{mV}$, if not stated otherwise. Cells with $>80 \mathrm{pA}$ of leak current were discarded. Uncompensated series resistance was between 3 and $7 \mathrm{M} \Omega$. Recordings were visualized and analyzed using jClamp (SciSoft), OriginPro 8.6 (OriginLabs), Excel (Microsoft), and Clampfit (Molecular Devices). Graphs were generated with OriginPro 8.6 (OriginLab) and Adobe Illustrator (Adobe, CS4).

Single-channel recordings. After achieving whole-cell configuration and verification of the cell's health status (peak MET current, $\sim 1 \mathrm{nA}$; leak current, $<75 \mathrm{pA}$; series resistance, $<7 \mathrm{M} \Omega$ ), $5 \mathrm{~mm}$ BAPTA was applied perpendicular to the hair bundle's axis of sensitivity and the elicited MET current recorded simultaneously. Because of the treatment, tip links break and the MET current rapidly declines. A custom-built fluid-jet stimulator was subsequently used to elicit single-channel responses. In $\sim 5 \%$ of conducted experiments, single-channel events were observed (in others, either too many channels were still active or all were lost). Subtracting the individual baseline current from each recorded single event normalized the current to its closed state. In most cases, the hair cells 
were first treated with BAPTA followed by PAO treatment. In those cases, single-channel events $>20$ min after PAO application were counted as PAO treated. In some cases, PAO was applied first and BAPTA after the known PAO effects were established. Those recorded events were not different from the ones treated with BAPTA first and PAO later. The recorded events were transferred into histograms and analyzed using Clampfit (Molecular Devices) and OriginPro 8.6 (OriginLab). Gaussian fits with two peaks were run on those histograms and the current difference between the fitted closed-state and open-state peaks was measured as single-channel current. The single-channel currents under control conditions and after PAO treatment were averaged. Single-channel conductance was calculated based on single-channel current and membrane holding potentials and averaged between experiments. Data show means with SD.

Reversal potential. We recorded the MET current to identical step stimuli at different membrane holdings potentials, stepping from -184 to $+116 \mathrm{mV}$ in $20 \mathrm{mV}$ increments and normalized those responses to the MET current amplitude at $-184 \mathrm{mV}$. These IXIV (current-displacement, current-voltage) plots were subsequently fitted with a single-site binding model (see Eq. 3) and the fit parameters from each cell averaged (Kros et al., 1992; Farris et al., 2004).

Actuation. Hair bundles were either stimulated by a piezo-driven stiff glass probe or a fluid-jet system. For stiff-probe stimulation, borosilicate glass pipettes were fire-polished to match the geometry of P8-P10 IHC bundles and driven by a piezoelectric stack (Thorlabs, AE0505D08F). Stimulus voltages were low-pass filtered at $10-30 \mathrm{kHz}$ with an eight-pole Bessel filter (Frequency Devices, L8L 90PF) coming from the digitialto-analog converter (IOtech, daq3000), after an adjustable attenuator (Tucker Davis, PA5), and before being sent to a high-voltage amplifier to drive the piezoelectric stack. Probe displacements were calibrated before each experiment using an optical grid and the driving voltage/displacement ratio recorded. Before each experiment, the glass probe was cleaned with Chromerge. While focused on the top of the first row stereocilia, the probe was lowered until it was in the same focal plane as that first row. While the piezoelectric stack was constantly driven by a step stimulation, the probe was lowered toward the bundle until good contact and current response was achieved. Stimulus intensities were adjusted to ensure a full activation curve response that saturated at negative and positive displacements.

The fluid jet used a piezoelectric disc bender, which drove fluid stimulation through a pipette with a diameter of $8-20 \mu \mathrm{m}$. The voltage stimulus to drive the disc bender was filtered at $1 \mathrm{kHz}$ with an eight-pole Bessel Filter (Frequency Devices). For every fluid-jet stimulation, the position of the central part of the hair bundle was tracked using high-speed imaging of the stimulation at 10,000 frames per second using the Phantom Miro 320s (Vision Research) and extracted using a Gaussian fit to a bandpass-filtered hairbundle image-intensity profile (MathWorks, Matlab).

$\mathrm{Ca}^{2+}$ imaging. The hair bundle was stimulated with the same fluid jet as described above. Fluorescents images of Fluo-4FF and AlexaFluor 594 together with bright-field images were used to identify and measure fluorescent changes in single second-row stereocilia as previously described (Beurg et al., 2009). The Fluo-4FF fluorescent images were acquired at $500 \mathrm{~Hz}$ and regions of interest for single stereocilia marked. Subsequently single-stereocilium responses were averaged for each measured cell. Stereocilia from the second row were mostly imaged and a similar focal plane was used before and after drug treatment so that the same population of stereocilia were imaged in each condition. The stimulus protocol consisted of a depolarization step from -84 to $+76 \mathrm{mV}$, a mechanical deflection of the bundle toward its tallest row, while depolarized, followed by a repolarization during the mechanical step (to maximize the fluorescent signal), and a subsequent relaxation of the mechanical stimulus back to the resting position. Mechanical stimuli were applied with a fluid jet and with sufficient amplitude to elicit $\sim 75 \%$ of maximal MET current, to avoid mechanical damage to the hair bundle.

$\mathrm{PIP}_{2}$ immunostaining in P8-P22 rat cochlea explants. $\mathrm{PIP}_{2}$ labeling in the organ of Corti was described previously (Phillips et al., 2006). Briefly, explants were fixed in $4 \%$ paraformaldehyde in $0.1 \mathrm{~m}$ sodium phosphate buffer at $\mathrm{pH}$ 7.2. The tissue was permeabilized with $1 \%(\mathrm{w} / \mathrm{v})$ sarkosyl in PBS for $1 \mathrm{~h}$, blocked for $1 \mathrm{~h}$ with $5 \mathrm{mg} / \mathrm{ml} \mathrm{BSA}$ in Tris-buffered saline
(TBS; 10 mm Tris-HCl, pH 7.4, $150 \mathrm{~mm} \mathrm{NaCl}$ ), and incubated overnight at $4^{\circ} \mathrm{C}$ in blocking buffer containing anti-PIP ${ }_{2}$ monoclonal antibody (1: 200 dilution, clone 2C11; Invitrogen, MA3-500, lot number PB200026). The tissue was washed in blocking buffer, incubated with Alexa Fluor 488-conjugated donkey anti-mouse IgG secondary antibody ( $1: 600$ dilution; Invitrogen) for $1 \mathrm{~h}$, followed by staining with Alexa Fluor 546conjugated phalloidin (1:200 dilution; Invitrogen) in TBS for $20 \mathrm{~min}$. Tissues were washed, mounted (Invitrogen, Antifade Gold), and imaged on a confocal microscope (Zeiss, LSM880).

Immunohistochemistry imaging. Identical microscope settings allowed for a normalization of fluorescence intensity after PAO treatment to the average control intensity for each tissue preparation $(n \geq 5)$. The resulting stack images were analyzed using Imaris 8.3 (Bitplane). The spotdetection algorithm was applied on selected volumes of interest that encompassed single hair bundles. For outer hair cells (OHCs), the spot cutoff size was $180 \mathrm{~nm}$ and smaller spots were not counted, for IHCs the size was $220 \mathrm{~nm}$. Spots per hair bundle were counted and averaged as per cell for a given tissue. The intensity values of those spots were normalized to the average intensity of spots in each tissue. Spot intensities in PAOtreated tissues were normalized to the average fluorescent intensity of the parallel-processed control tissue. In two experiments, tissue used for hair-cell MET current recordings was also immunohistochemically processed. In those cases, the control measurements were taken from an area far away and upstream of the PAO application puff site. Those fluorescent intensities were not different from other measured controls (using identical microscope settings).

Analysis. We used the following Boltzmann equation to fit the current displacement plots (Eq. 1):

$$
f(x)=y_{0}+\frac{I_{\max }}{\left(1+e^{\left(x_{0}-x\right) * z_{1}} * e^{\left(x_{0}-x\right) * z_{2}}\right)}
$$

$y_{0}$ is the $y$-intercept to accommodate mechanically insensitive MET channels after drug application. $I_{\max }$ is the asymptotic maximum, $x_{0}$ is the set point, and $z_{1}$ and $z_{2}$ are the slopes.

The following exponential decay equation was used to fit the current decline at $50 \% I_{\max }$ (Eq. 2):

$$
f(x)=y_{0}+A_{1} e^{-\left(x-x_{0}\right) / \tau_{1}}+A_{2} e^{-\left(x-x_{0}\right) / \tau_{2}}
$$

where $\tau_{1}$ and $\tau_{2}$ are the time constants and $A_{1}$ and $A_{2}$ are the respective amplitudes. $x_{0}$ is used to shift the fit in time. Double and single exponential fits were evaluated using the Akaike information criterion (AIC), which measures the relative quality of fits and penalizes excess parameters.

Single-site blocking model. For the single-site blocking model, we used the following equation (Eq. 3):

$$
I / I_{\max }=k\left(e^{\frac{(1-\delta)\left(V-V_{r}\right)}{V_{s}}}-e^{\frac{-\delta\left(V-V_{r}\right)}{V_{s}}}\right)
$$

where $k$ is the proportionality constant, $\delta$ is the fractional distance of the blocking site through the membrane's electrical field, $V_{\mathrm{r}}$ is the reversal potential, and $V_{\mathrm{s}}$ is the steepness of rectification.

Data availability. The data that support the findings of this study are available from the corresponding author upon reasonable request.

Experimental design and statistical analysis. Experiments were designed to avoid any bias of data by ensuring equal use of both sexes and randomization of drug and control experiments. When possible, immunohistochemical experiments were performed on tissues that underwent electrophysiological examination, allowing for collection of data for the same tissue with and without drug treatment. When possible, a complete dataset was acquired for a given cell before and after treatment. These datasets included current-displacement stimuli, paired-pulse stimuli (both at negative and positive holding potentials), and currentdisplacement/current-voltage stimuli. This was done to minimize animal use and to allow for a good comparability between treated-tissue and untreated-tissue data. The minimal sample size was predetermined by the historical variance observed between cells and an expectation of detecting $\geq 10 \%$ change in response. 
A

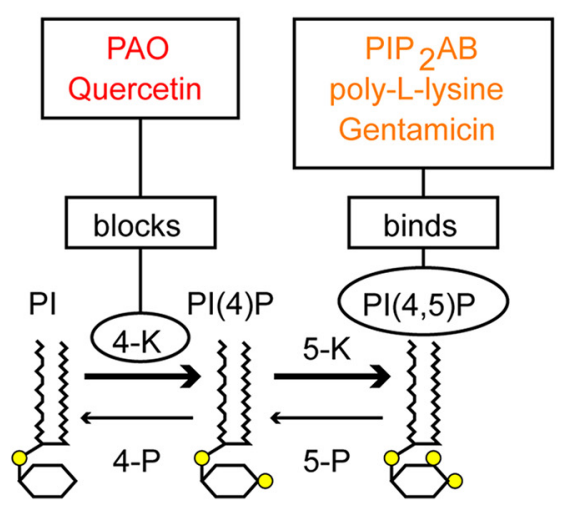

B
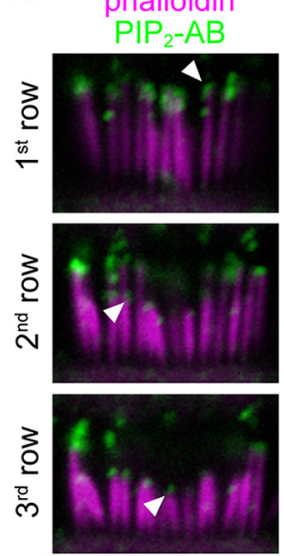

control
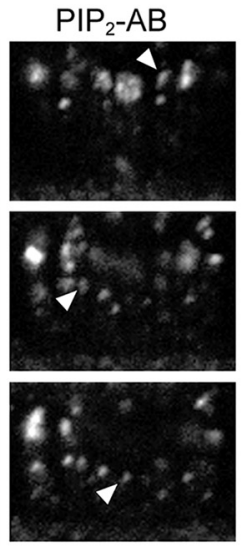

PAO

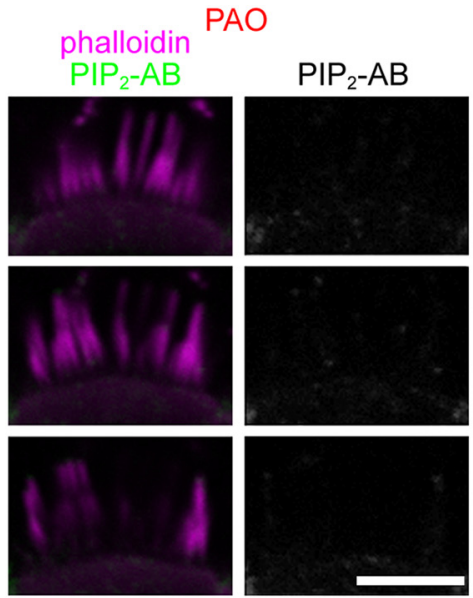

C
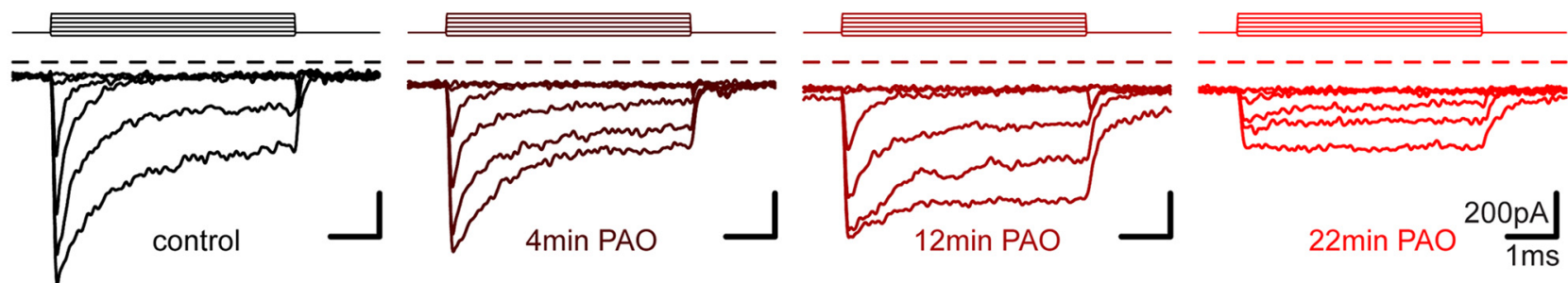

Figure 1. PIP ${ }_{2}$ depletion affects MET currents in IHCS. Different pharmacological methods are available to affect free PIP ${ }_{2}$ level in a cell, which in turn affect the MET current in mammalian IHCS. $A$, Similar effects on the MET current are elicited by compounds, such as quercetin or PA0, which target 4-K, blocking PIP, replenishment, and by compounds that compete for binding of PIP ${ }_{2}$, such as a $\mathrm{PIP}_{2}-\mathrm{AB}$, poly--Llysine, or gentamicin. $\boldsymbol{B}$, Immunolabeling of an $\mathrm{IHC}_{\mathrm{C}}$ hair bundle with phalloidin (purple, staining actin) and a $\mathrm{PIP}_{2}-\mathrm{AB}_{\text {(green, grayscale). Strongest } \mathrm{PIP}}$ signals are observed at stereocilia tips. PIP 2 labeling is drastically reduced after PA0 treatment. Arrowheads indicate labeling at tips of first-row, second-row, and third-row stereocilia. $C$, Time course of $100 \mu \mathrm{m}$ PA0 effects on MET-current responses to a family of mechanical step stimuli, compared with controls (black). Observed effects are as follows: a reduced peak current, an increased baseline current, and reduced adaptation. These responses manifested over time (black to red traces), with the baseline current increasing first, followed by a loss of peak current, and a reduction of adaptation.

Significances were calculated using Student's two-tailed $t$ tests from Excel (Microsoft). $P$ values for comparisons within a cell were paired and for tests between different cells unpaired with unequal variance conditions. Significance levels were as follows: ${ }^{*} p<0.05,{ }^{* *} p<0.01,{ }^{* *} p<$ 0.001 . Data are presented as mean $\pm \mathrm{SD}$, unless otherwise noted. The AIC was used to compare the quality of different fitting equations for the time courses of MET current adaptation.

\section{Results}

Loss of free PIP ${ }_{2}$ affects MET currents

We reduced the functional PIP ${ }_{2}$ membrane levels in three ways: (1) with PAO and quercetin, we blocked phosphatidylinositol-4kinase $(4-\mathrm{K})$, preventing synthesis of $\mathrm{PIP}_{2} ;(2)$ using a $\mathrm{PIP}_{2}-\mathrm{AB}$ and gentamicin, we blocked existing $\mathrm{PIP}_{2}$; and (3) with poly-Llysine, we bound and extracted $\operatorname{PIP}_{2}$ (Fig. 1a). We mostly used $\mathrm{PAO}$ as it was easiest to solubilize, easy to apply (compared with intracellular compounds), and allowed for cells to act as their own control. The other compounds were used to establish the $\mathrm{PIP}_{2}$ specificity of the observed effects. Similar effects were observed on METcurrent responses independent of the employed drug, attesting to the ability to selectively target $\mathrm{PIP}_{2}$ pharmacologically. The observed effects included the following: (1) a reduction of peak MET-current amplitude, (2) an increase in MET channels open at rest, (3) a loss of a fast component of adaptation, (4) a delay of MET-current onset after stimulation, (5) an increase in METcurrent rise time, and (6) changes to single-channel pore properties. All effects were irreversible during the time frame of the experiments ( $\leq 60 \mathrm{~min})$. Each effect is discussed in detail below. For intracellularly applied compounds, the effects were established and stable after $\sim 10 \mathrm{~min}$, while extracellular application required $\sim 20 \mathrm{~min}$ (Fig. 1c). Intracellular $\mathrm{PIP}_{2}$ served as a control for selectivity by preventing the measured effects ascribed to $\mathrm{PIP}_{2}$ reduction.

\section{Reduction of PIP ${ }_{2}$ labeling in IHCs and OHCs after PAO treatment}

$\mathrm{PIP}_{2}$ labeling was strongest at tips of first-row stereocilia in IHCs and OHCs (Fig. 1b). Second-row and third-row stereocilia were also labeled (Figs. 1b, 3a, arrowheads) but appeared fainter, likely because of the smaller diameter of second-row and third-row stereocilia. The observed labeling correlated well with a previous SEM study of guinea pig inner ear hair-cells that showed PIP $_{2}$ immunogold labeling along the shaft and at the tips of stereocilia (Tachibana et al., 1984). However, our staining data were slightly different from those reported in mice (Phillips et al., 2006; Goodyear et al., 2008) and bullfrog (Hirono et al., 2004), where stereocilia shafts were also labeled. While the two studies conducted in mice (Phillips et al., 2006; Goodyear et al., 2008) used a transfected construct of GFP and the PIP ${ }_{2}$-binding domain of PLC $\delta 1$ ( $\mathrm{PH}$ domain) on cultured organs of Corti, the bullfrog study used a monoclonal $\mathrm{PIP}_{2}$ antibody (2C11) on isolated, fixed hair cells (Hirono et al., 2004). While the GFP/PH domain construct would only detect to intracellular leaflet $\mathrm{PIP}_{2}$, the antibody should detect both intracellular and extracellular leaflet PIP $_{2}$. The fixation and permeabilization methods also influence the results. For example, in our case, we needed to use sarkosyl as detergent for the best results. Without detergent or with Triton X instead of sarkosyl, the $\mathrm{PIP}_{2}$ labeling was fainter or absent, similar to previous results (Hirono et al., 2004). Nonetheless, using older rats, we 

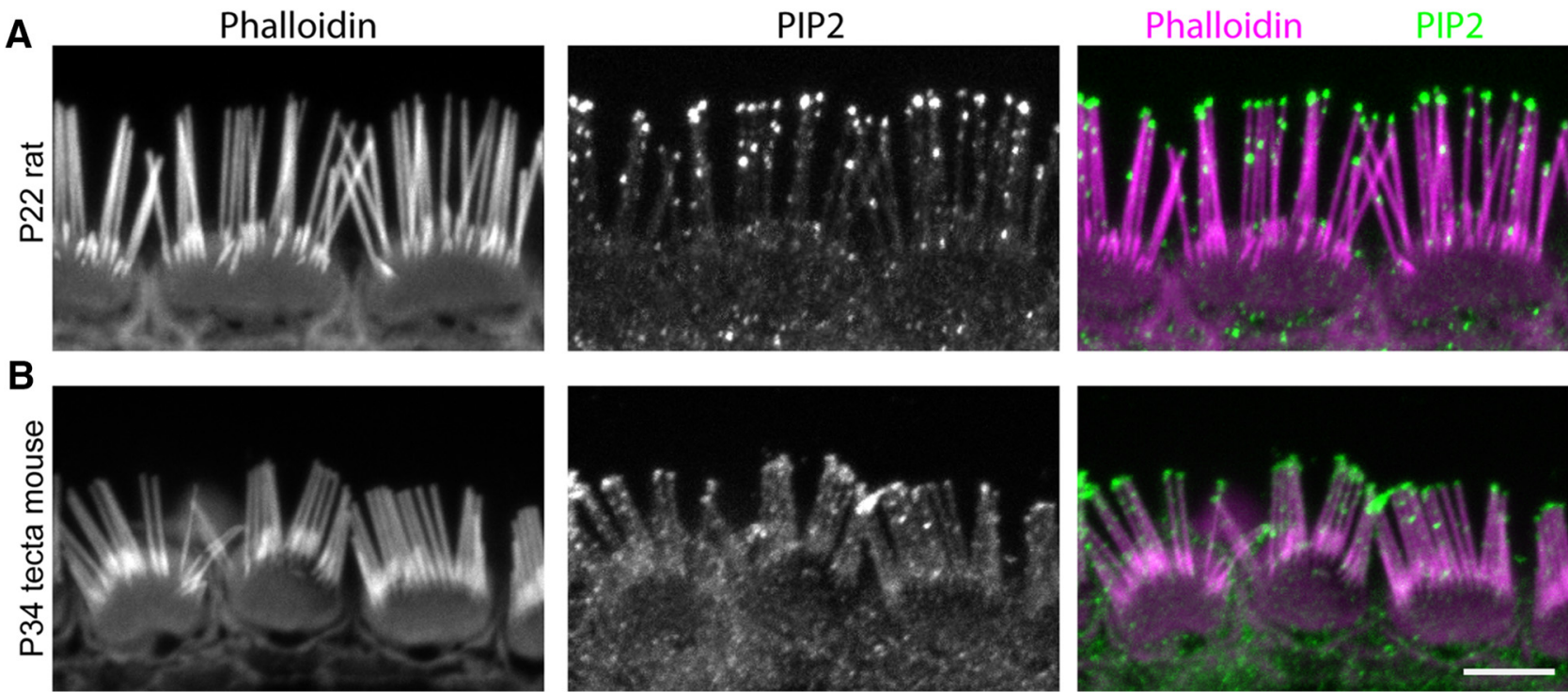

Figure 2. Immunohistochemical labeling of a P22 rat and a P34 Tecta mouse. $\boldsymbol{A}$, Left to right, Actin labeled with phalloidin, PIP labeling, and overlay. Compared with younger animals ( $<$ P10), a faint labeling of the shaft stereocilia is also visible. $\boldsymbol{B}$, Left to right, Actin labeled with phalloidin, PIP ${ }_{2}$ labeling, and overlay. The stereocilia shafts are clearly labeled for PIP ${ }_{2}$ but the foci of labeling at stereocilia tips remain.

better reproduced previous data from mice (Phillips et al., 2006; Goodyear et al., 2008), suggesting age rather than species differences in the data (Fig. 2a). Additionally, we used Tecta mutant mice (with detached tectorial membrane) and found persistent stereociliary tip labeling (Fig. $2 b$ ). In conclusion, we were able to establish a reliable $\mathrm{PIP}_{2}$ staining protocol, which was sufficient to test whether PAO treatment affects $\mathrm{PIP}_{2}$ levels.

$\mathrm{PIP}_{2}$ foci counts in all stereocilia rows of IHCs and OHCs were significantly reduced after PAO treatment (IHCs: before PAO treatment, $17 \pm 5$; after PAO treatment, $6 \pm 2$; Fig. $3 b$; $n=5$; $\mathrm{OHCs}$ ) and $\mathrm{OHC}$ (before PAO treatment, $13 \pm 3$; after PAO treatment, $4 \pm 1$, Fig. $3 c ; n=5$ ), the reduction was equally spread over all stereocilium rows. Only clear foci of $\geq 180 \mathrm{~nm}$ (OHCs) or $220 \mathrm{~nm}$ (IHCs) were counted. In addition, the fluorescence intensity of remaining $\mathrm{PIP}_{2}$ labeling after $\mathrm{PAO}$ treatment was significantly decreased compared with controls (Fig. 3e) for IHCs $\left(-44 \pm 26 \%, p=2.1 * 10^{-43}\right)$ and OHCs $(-43 \pm 28 \%, p=5.1 *$ $\left.10^{-58}\right)$. In two experiments, we compared PAO effects on MET current relative to the remaining $\mathrm{PIP}_{2}$ labeling (Fig. $3 e$ ) in the same tissue. We analyzed labeled hair bundles upstream (control) and downstream (treated) of the PAO application site (Fig. $3 a$ ), finding a correlation between severity of MET-current effects and $\mathrm{PIP}_{2}$ labeling (Fig. $3 c-e$ ).

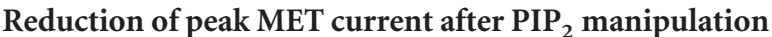

The peak MET current decreased significantly $\left(p=6 \times 10^{-8}\right)$ from $-907 \pm 179 \mathrm{pA}$ in controls $(n=29)$ to $-601 \pm 130 \mathrm{pA}$ after $>15$ min of PAO treatment $(n=22)$ and from $-759 \pm 137 \mathrm{pA}$ (controls, $n=12)$ to $-492 \pm 98 \mathrm{pA}(n=12, p=0.0003)$ after $>15$ min of treatment with other compounds, independent of stimulus method (stiff probe or fluid jet). The MET currents of untreated controls did not significantly decrease during the same time frame (before treatment, $-860 \pm 79 \mathrm{pA}$; after treatment, $-834 \pm 119 \mathrm{pA}, n=5, p=0.37)$. The PAO and other compound effects were not significantly different from one another. Intracellular $\mathrm{PIP}_{2}$ application did not significantly $(p=0.64)$ affect peak MET current $(-895 \pm 273 \mathrm{pA} ; n=9)$ compared with controls and protected against PAO treatment $(-836 \pm 314 \mathrm{pA}$; $n=9)$.
Increased baseline current reflects an increased number of open MET channels

The baseline current increased after $\mathrm{PIP}_{2}$ manipulations. Negative hair-bundle displacements, using either a stiff-probe stimulator or a fluid jet, were less effective at closing channels and reducing this standing current (Fig. $4 f$ ). However, application of $1 \mathrm{mM}$ curare, a known MET-channel blocker (Glowatzki et al., 1997), or 5 mм BAPTA, known to break tip links, resulting in channel closure (Crawford et al., 1991), reduced the baseline current increase (Fig. $4 a-d$ ), suggesting that it is MET current that no longer responds to negative hair-bundle stimulation. The control baseline current increased from $-65 \pm 16$ to $-190 \pm 42 \mathrm{pA}$ after PAO treatment ( $p=0.0015$ compared with control), and was reduced to $-79 \pm 25 \mathrm{pA}(p=0.00085$ compared with after PAO treatment; $p=0.042$ compared with control) after curare application (Fig. $4 a, b ; n=5$ ). When using BAPTA, the control baseline increased from $-74 \pm 18$ to $-135 \pm 20 \mathrm{pA}$ after PAO treatment $(p=0.00048$ compared with control), and returned to $-80 \pm 16 \mathrm{pA}(p=0.0074$ compared with after PAO treatment; $p=0.335$ compared with control) after BAPTA application (Fig. $4 c, d ; n=5)$. The baseline current increase after PAO treatment was accompanied by an increase of intracellular $\mathrm{Ca}^{2+}$ levels (monitored with Fluo-4FF), which could be blocked by curare (Fig. $4 e$ ). These data suggest that $\sim 90 \%$ of the baseline current increase is MET current and the remaining 10\% leak current. Thus, we calculated the proportion of standing MET current for all treated cells, where for PAO treatment it represents $18 \pm 8 \%$ ( $n=12$; controls, $2 \pm 1 \%, n=19$ ) of the total current and for the other compounds $12 \pm 6 \%$ (Fig. $4 g ; n=12$; controls, $2 \pm 1 \%$, $n=12)$. Intracellular $\mathrm{PIP}_{2}$ application protected against the $\mathrm{PAO}$ effect (internal PIP $2: 2 \pm 1 \%$ PIP $_{2}+$ PAO: $4 \pm 2 \% ; n=9$ ). Strong fluid-jet pulls were insufficient to close all MET channels, indicating that some channels became mechanically insensitive. These data show that more MET channels are in an open state at rest and less sensitive to mechanical stimuli after $\mathrm{PIP}_{2}$ manipulations, suggesting that $\mathrm{PIP}_{2}$ is important for channel gating and/or force relay to the channel. A similar result was obtained in bullfrog, though not quantified (Hirono et al., 2004). Mechanically insensitive MET channels have previously been reported for iso- 

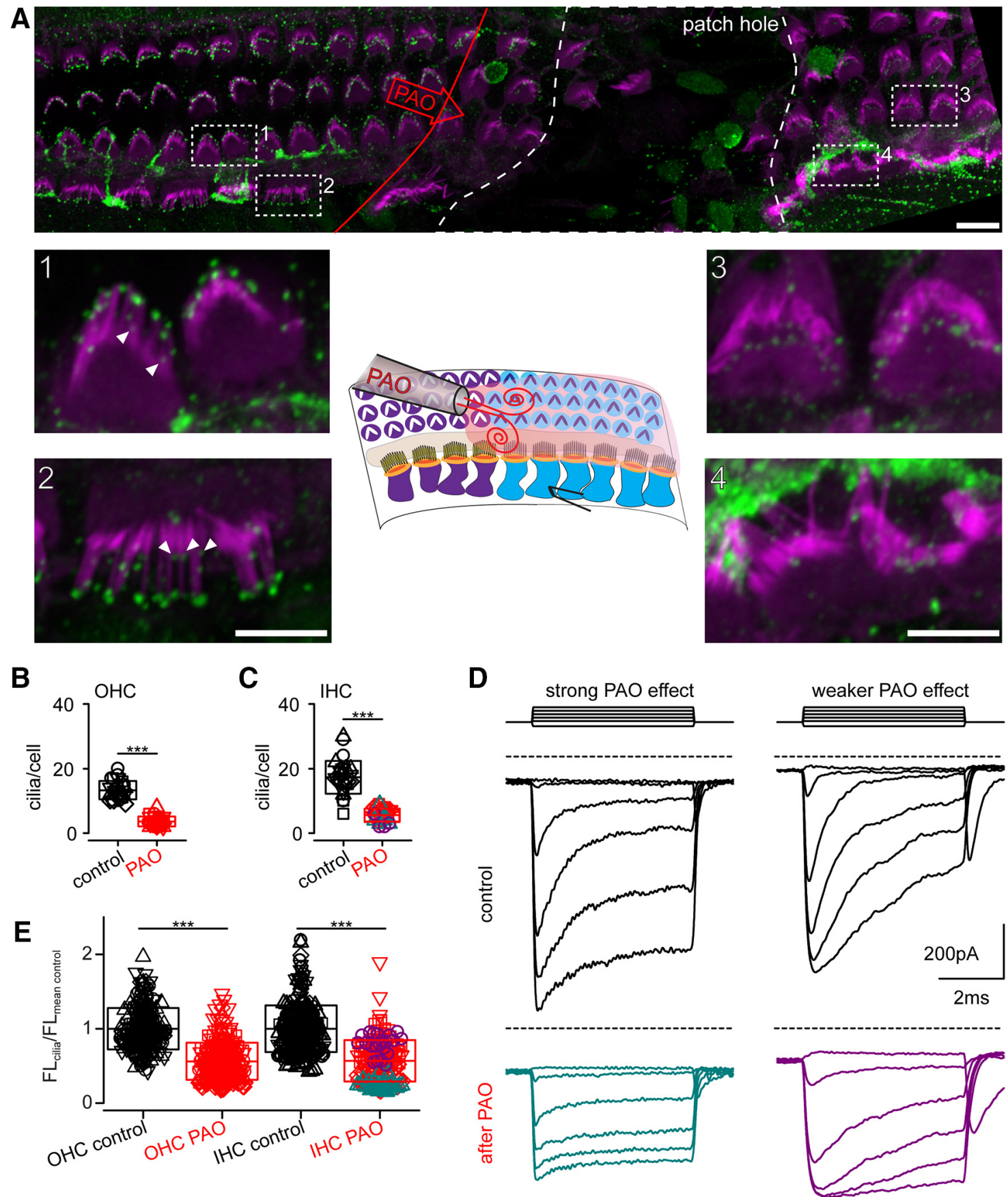

Figure 3. Comparison of immunohistochemistry with MET-current recordings. A, Immunohistochemical picture of rat cochlear preparation after whole-cell patch experiment. The red line indicates the presumed border of PA0-treated and untreated cells. This border is based on the positioning of the PA0 puffer. A constant, apical perfusion, flowing over the tissue from left to right, ensured that no PAO reached the left cell. 1-4, Examples of $\mathrm{OHC}(1,3)$ and $\mathrm{IHC}(2,4)$ treated (right) and untreated (left). The diagram illustrates the experimental setup. $\boldsymbol{B}$, Count of labeled cilia per IHC for PAO-treated and untreated cells. Different symbols correspond to different cells. The color code for PA0-treated cells corresponds to traces in D. C, Count of labeled cilia per IHC for PA0-treated and untreated cells. Different symbols correspond to different cells. D, MET-current examples for cells that showed a strong or weak PA0 effect after treatment. The strong effect showing a larger baseline increase, less peak MET current, loss of adaptation. $\boldsymbol{E}$, Fluorescent intensity of remaining PIP 2 labeling in $\mathrm{OHC}$ and IHC in untreated and treated examples. The color code for treated IHC corresponds to colors in $\boldsymbol{D}$. The data show a correlation between remaining $\mathrm{PIP}_{2}$ labeling and the strength of MET-current effects. ${ }^{*} p<0.05,{ }^{* *} p<0.01,{ }^{* * *} p<0.001$. Boxes represent $\mathrm{SD}$ and the line in the middle of the mean.

lated guinea pig hair cells following treatment that breaks tip links (Meyer et al., 1998, 2005).

\section{Reduction in extent of adaptation and loss of a fast} adaptation component

Current adaptation during static stimulation is a hallmark of the auditory MET process. We investigated adaptation in the dynam- ic/temporal domain and in steady-state conditions. Dynamic adaptation was measured as the ratio of the current level before the end of the step stimulus and the peak current during a 5-ms-long step displacement that elicited half-maximal MET current (Fig. $5 a$, black arrow). In controls, the extent of adaptation was $90 \pm$ $10 \%(n=10)$ and decreased significantly $\left(p=9.9 \times 10^{-6}\right)$ to $24 \pm 14 \%(n=10)$ after PAO treatment (Fig. $5 b)$. The other 

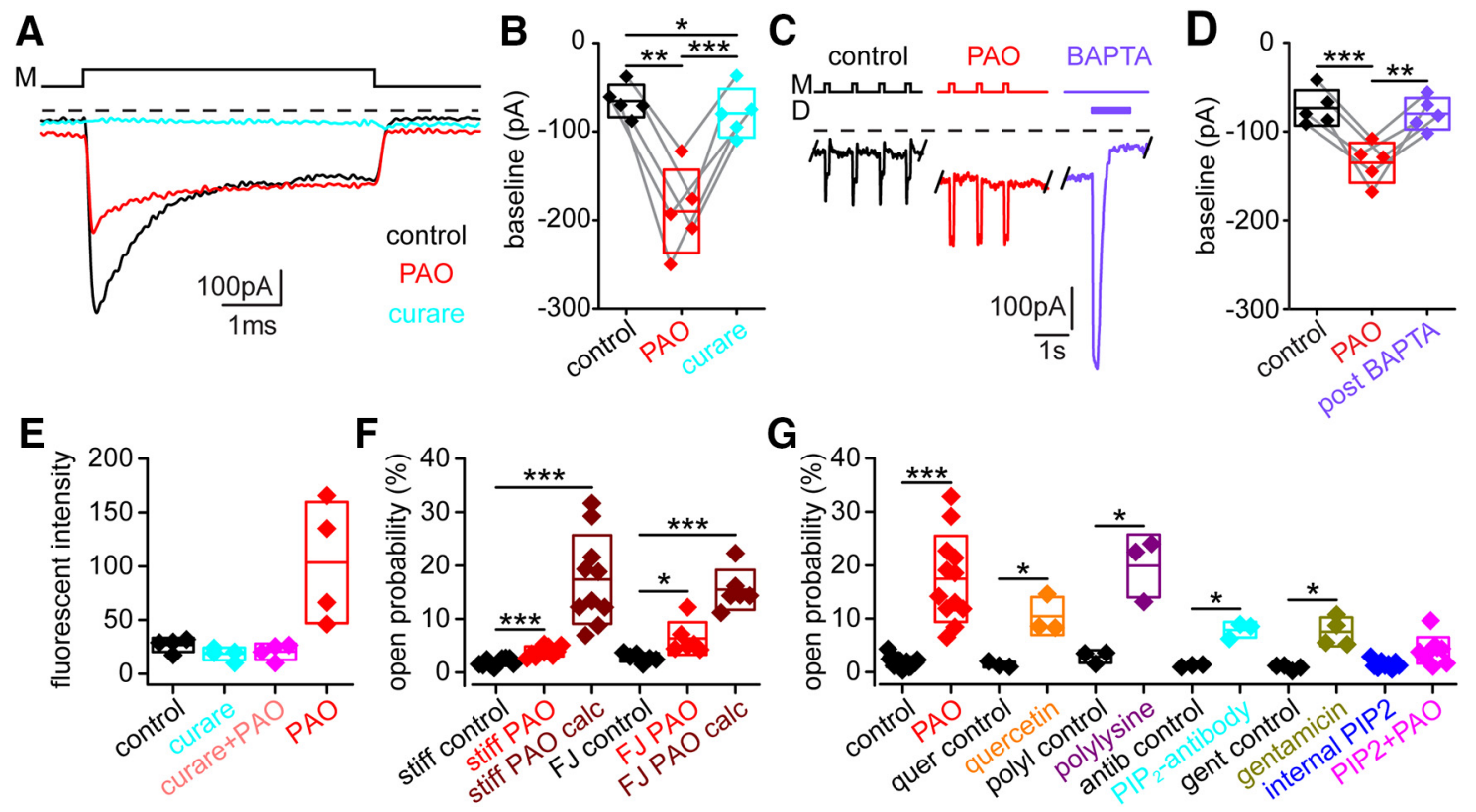

Figure 4. Baseline current and open probability effects. $A$, Half-maximal current responses to a step stimulus (M). The dashed line represents 0 pA. After PA0 treatment (red), the baseline current increases beyond the control baseline (black). After the PAO effect was established, $1 \mathrm{~mm}$ curare, an open MET-channel blocker, was applied. Curare application returned the baseline current to control levels, indicating the baseline change was due to an increase in open MET channels. $\boldsymbol{B}$, Summary plot of five cells (gray lines connecting individual cells) where the baseline was measured before ( $66 \pm 16 \mathrm{pA}$, black) and after PAO (190 $\pm 42 \mathrm{pA}$, red), and after curare application (79 $\pm 25 \mathrm{pA}$, cyan). The PA0-treated baseline was significantly different from baselines controls ( $p=$ $0.0015)$ and baselines during curare application $(p=0.00085)$. Curare blocked $90 \%$ of the PA0-induced baseline shift but differed from the control baseline $(p=0.042)$. C, Current responses to mechanical stimuli (shown above) before (black) and after PA0 treatment (red), and during a $5 \mathrm{~mm}$ BAPTA puff (purple). D, BAPTA puff. The baseline increased from controls (black) to the PA0 condition (red). The BAPTA puff (violet bar) stimulates the bundle, removes the $\mathrm{Ca}^{2+}$ block, and breaks tip links. This is apparent by the strong inward current after puff onset and the rapid reduction of that current thereafter, showing that the baseline increase depends on the tip link. $D$, Summary plot of baseline levels in five cells before ( $74 \pm 18 \mathrm{pA}$, black) and after PAO (135 $\pm 20 \mathrm{pA}$, red) treatment, and after a $5 \mathrm{~mm}$ BAPTA puff ( $80 \pm 16 \mathrm{pA}$, violet). The PA0-treated baseline current was significantly different from that of controls $(p=0.00048)$ and that measured after BAPTA treatment $(p=0.0074)$. The baseline currents of controls and after BAPTA treatment were not significantly different $(p=0.335)$. $\boldsymbol{E}$, The baseline fluorescent signal of the $\mathrm{Ca}^{2+}$ indicator dye Fluo-4FF increased after PAO treatment. This signal could be blocked by curare application during PAO application, indicating that the increase is due to a higher number of channels open at rest. $\boldsymbol{F}$, Plot of resting open probability in controls (black), after PAO treatment (red) based on mechanical pulls with either a stiff probe (stiff) or a fluid jet (FJ), and calculated open probability assuming baseline shift is $90 \%$ MET current (dark red). Fluid-jet pulls close more channels than stiff-probe pulls. G, Based on data from $\boldsymbol{A}-\boldsymbol{F}$, resting open probability was calculated for all tested conditions. Additionally, results from the other tested drugs are also shown (orange, quercitin; violet, poly-L-lysine; cyan, $\mathrm{PIP}_{2}$-AB; dark yellow, gentamicin). Intracellular PIP ${ }_{2}($ blue) protected against $\mathrm{PA0}$ effect (purple). ${ }^{*} p<0.05,{ }^{* *} p<0.01,{ }^{* * *} p<0.001$. Boxes represent SD and the line in the middle the mean.

tested compounds similarly reduced the extent of adaptation (quercitin: $87 \pm 10$ to $55 \pm 7 \%$; poly-L-lysine: $59 \pm 9$ to $34 \pm 9 \%$; $\mathrm{PIP}_{2}-\mathrm{AB}$ : $65 \pm 7$ to $30 \pm 3 \%$; gentamicin: $67 \pm 11$ to $41 \pm 5 \%$; Fig. $5 b$ ). The intracellular compound controls were different from PAO controls, likely due to early drug-action onset compared with external application of PAO and quercetin. Intracellular $\mathrm{PIP}_{2}$ application did not affect the extent of adaptation $(88 \pm 8 \%, n=7)$ and protected against $\mathrm{PAO}$ treatment $\left(\mathrm{PIP}_{2}+\right.$ PAO: $84 \pm 10 \%, n=7$; Fig. $5 b$ ).

Aside from the reduction in adaptation extent, we also identified kinetic changes in adaptation. Controls required a double exponential decay fit (Eq. 2) to sufficiently describe the METcurrent decay during stimulation, with the following time constants: $\tau_{1}=142 \pm 60 \mu \mathrm{s}$ and $\tau_{2}=971 \pm 389 \mu \mathrm{s}$ (Fig. $5 c, d ; n=$ 10). A double exponential fit was superior to a single exponential fit, tested with the AIC. After PAO treatment, a single exponential fit was sufficient (tested with AIC), with a time constant $\left(\tau_{\mathrm{PAO}}\right)$ of $1298 \pm 555 \mu$ s (Fig. $5 c, d ; n=10$ ), which was significantly different from $\tau_{1}(p=0.0014)$ but not $\tau_{2}(p=0.087$; Fig. $5 d)$. The other compound controls also required double exponential fits (with the following time constants: other- $\tau_{1}=158 \pm 83 \mu \mathrm{s}$; other $-\tau_{2}=1180 \pm 330 \mu \mathrm{s}$; Fig. $5 d$ ), which changed to a single exponential fit later $\left(\tau_{\text {other-drugs }}=996 \pm 414 \mu\right.$ s, different from other- $\tau_{1} ; p=0.0002$, but not from other- $\tau_{2}, p=0.16$ ). When $\mathrm{PIP}_{2}$ was included intracellularly a double exponential fit was required $\left(\mathrm{PIP}_{2} \tau_{1}=209 \pm 85 \mu \mathrm{s} ; \mathrm{PIP}_{2} \tau_{2}=1091 \pm 356 \mu\right.$ s; Fig.
$5 d)$, which did not change after PAO application $\left(\mathrm{PIP}_{2}+\mathrm{PAO}\right.$ $\tau_{1}=270 \pm 147 \mu \mathrm{s}, p=0.43, \mathrm{PIP}_{2}+\mathrm{PAO} \tau_{2}=1210 \pm 369 \mu \mathrm{s}$, $p=0.58$ ). These findings demonstrate the biological nature of fast adaptation (Peng et al., 2013), directly refuting the possibility of stimulus artifacts being the source of $\tau_{1}$, as previously suggested (Corns et al., 2014), because it is unlikely that a mechanical stimulus artifact would be biochemically modulated. It also shows that the fastest component of adaptation is dependent on $\mathrm{PIP}_{2}$.

\section{Reduction of steady-state adaptation}

Steady-state adaptation was tested with paired-pulse experiments (Fig. 5e), which also distinguish between adaptation and inactivation. By comparing the relative shift between two activation curves (Fig. 5e,f), before and during a static displacement, to the size of the static displacement, one can calculate the adaptive shift (Fig. $5 g$ ). For a static displacement eliciting $60-70 \%$ of the peak MET current, this adaptive shift was $73 \pm 4 \%$ in controls $(n=6)$ and significantly $\left(p=3.3 \times 10^{-5}\right)$ decreased to $28 \pm 10 \%$ after PAO treatment (Fig. $5 g$ ). The adaptive shift for the other compounds was also significantly $\left(p=3.2 \times 10^{-7}\right)$ reduced from $69 \pm 7$ to $34 \pm 8 \%$ (Fig. $5 g ; n=9$ ). Intracellular $\mathrm{PIP}_{2}$ did not significantly $(p=0.41)$ affect the adaptive shift $(66 \pm 12 \%, n=$ $6)$ and protected against $\mathrm{PAO}$ application $(60 \pm 4 \%, n=6)$. The adaptive shift reduction was comparable to the dynamic reduction in adaptation extent. Together, the observed effects on dy- 
A

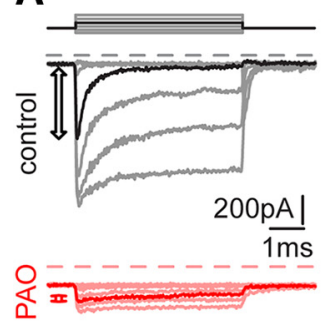

C
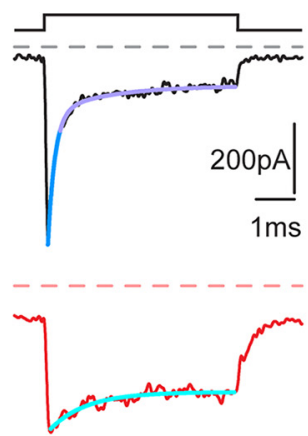

B

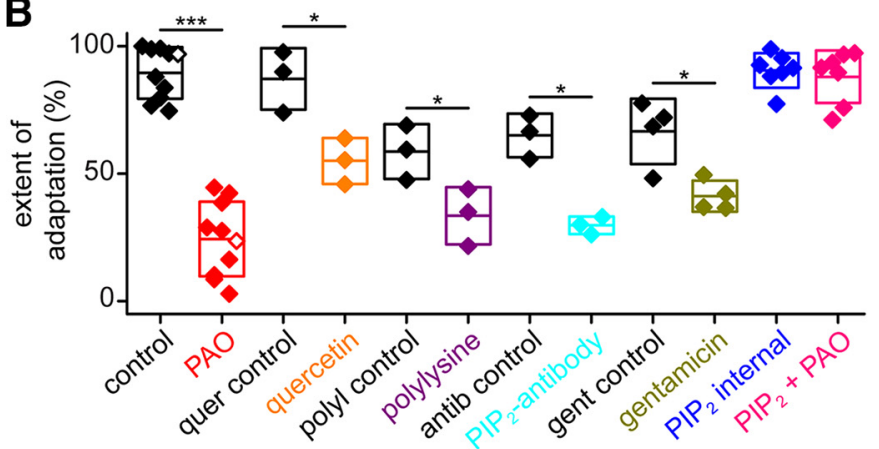

D

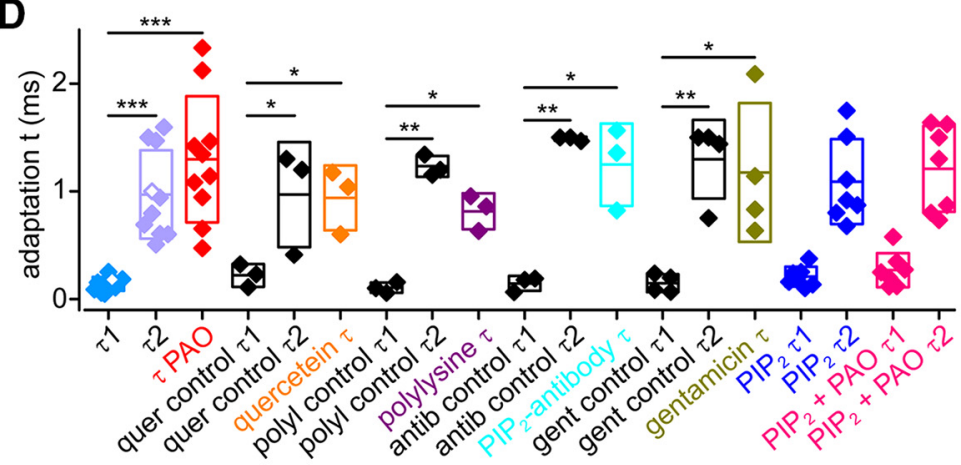

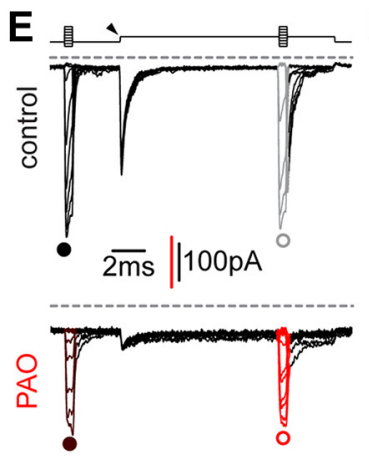
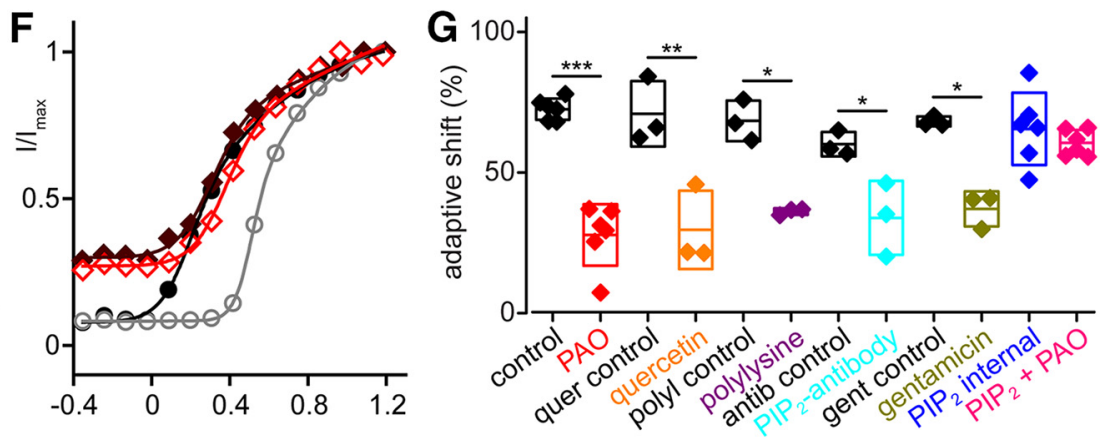

Figure 5. MET-current adaptation after PAO treatment. $\boldsymbol{A}$, Control and PAO-treated MET-current responses. Half-maximal traces and adaptation extent are highlighted (arrows on left). $B$, Summary plot of adaptation extent at half-maximal current for controls (black), PA0-treated (red), and separate controls (black) for each tested compound, and other compound treatments (orange, quercitin; violet, poly--Llysine; cyan, $\mathrm{PIP}_{2}-\mathrm{AB}$; dark yellow, gentamicin), $25 \mu \mathrm{m}$ internal PIP 2 (blue), and $25 \mu \mathrm{m}$ internal $\mathrm{PIP}_{2}+\mathrm{PAO}$ (purple). In controls, the adaptation extent was $87 \pm$ $11 \%$ and was reduced to $39 \pm 9 \%$ after PA0 treatment $(n=10)$. The other compounds showed a significant reduction from $70 \pm 15$ to $48 \pm 15 \%(n=9)$. The other compounds controls were significantly different from PAO controls $(p=0.006)$, which could be explained by the intracellular application of gentamicin, poly-L-lysine, and the PIP 2 -AB. Open symbols correspond to examples in $A$. Intracellular PIP (blue, $88 \pm 8 \%$ ) protected against PA0 treatment (purple, $84 \pm 10 \%$ ). C, Double exponential fit to a control half-maximal current response (black; $\tau_{1}$, light blue; $\tau_{2}$, light violet) and a single exponential fit (cyan) in the same cell after PAO treatment (red). A double exponential fit in controls and a single exponential fit in PA0-treated cells were the best fits (tested with AIC). D, Summary plot of time constants for control fits with $\tau_{1} 142 \pm 60 \mu$ s (light blue) and $\tau_{2} 971 \pm 389 \mu \mathrm{s}$ (light violet; $n=10$ ) and single exponential fits after PA0 treatment with $\tau_{\text {PA0 }} 1298 \pm$ $555 \mu \mathrm{s}$ (cyan; $n=10$ ). Other compound controls also required a double exponential fit with for other- $\tau 158 \pm 83 \mu$ s and other- $\tau_{1} 1180 \pm 330 \mu$ s. A single exponential fit was sufficient after drug treatments with $\tau$-other compounds $996 \pm 414 \mu \mathrm{s}$ (orange, quercitin; violet, poly-L-lysine; cyan, PIP,-AB; dark yellow, gentamicin). Open symbols correspond to examples in C.E, Current responses to a paired-pulse stimulus protocol in without treatment (control; top) and after PAO treatment (bottom) in the same cell. The predisplacement was $\sim 400 \mathrm{~nm}$. $\boldsymbol{F}$, Current- displacement plots of traces in $\boldsymbol{D}$. Lines are double Boltzmann fits to data. The rightward shift of the predisplaced activation curve was reduced after PA0 treatment. $\mathbf{G}$, Summary data for the adaptive shift to a $400 \mathrm{~nm}$ predisplacement step in controls (black), PAO-treated (red), other drug controls (black), other compounds (orange, quercitin; violet, poly-L-lysine; cyan, PIP $-\mathrm{AB}$; dark yellow, gentamicin), PIP internal (blue), and PIP internal + PAO (magenta) cells. The adaptive shift decreased significantly from $73 \pm 4 \%$ in controls to $28 \pm 10 \%(n=6)$ for PA0 treatment. For the other compounds, the adaptive shift decreased from $69 \pm 7 \%$ in controls to $34 \pm 8 \%(n=9) 10 \mathrm{~min}$ after achieving whole-cell mode (20 min after quercetin application). The adaptive shift with intracellular PIP was $66 \pm 12$ and $60 \pm 4 \%$ after PA0 application, which was not significantly different $(n=6) .{ }^{*} p<0.05,{ }^{* *} p<0.01,{ }^{* * *} p<0.001$. Boxes represent SD and the line in the middle the mean.

namic and steady-state adaptation argue that $\mathrm{PIP}_{2}$ is required for the fastest components of adaptation.

\section{Unaffected hair-bundle compliance and slowed MET-current kinetics}

We used fluid-jet stimulation to test whether changes to the hairbundle compliance could account for the observed MET-current effects. Fluid-jet stimulation allows for the assessment of a free- standing hair bundle's mechanical properties and for these properties to dictate the current output. PAO treatment did not alter hair-bundle displacements in response to fluid-jet stimulation (Fig. 6a,b), indicating no effect on global hair-bundle compliance after $\mathrm{PIP}_{2}$ depletion. Baseline and peak MET-current effects (Fig. $6 c$ ) were comparable to stiff-probe stimulation. We did, however, observe a change in MET-channel activation. To date, METchannel activation kinetics match the stimulating probe's rise 
A

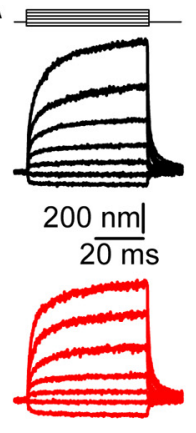

B

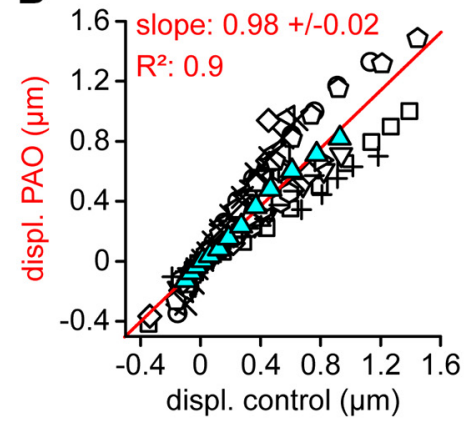

C

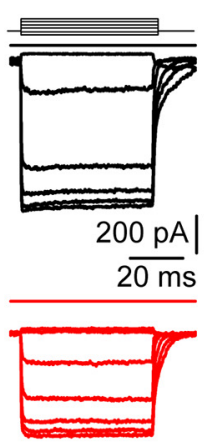

D

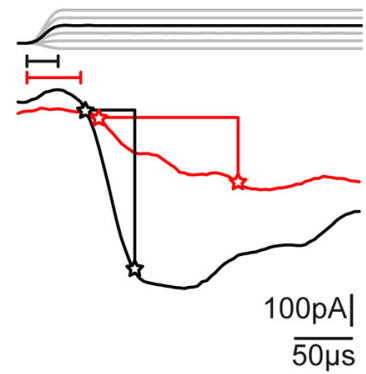

E

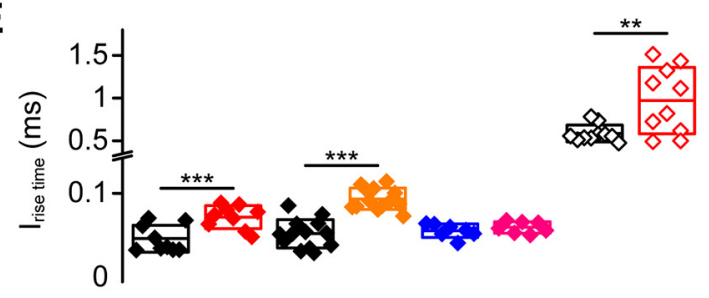

H

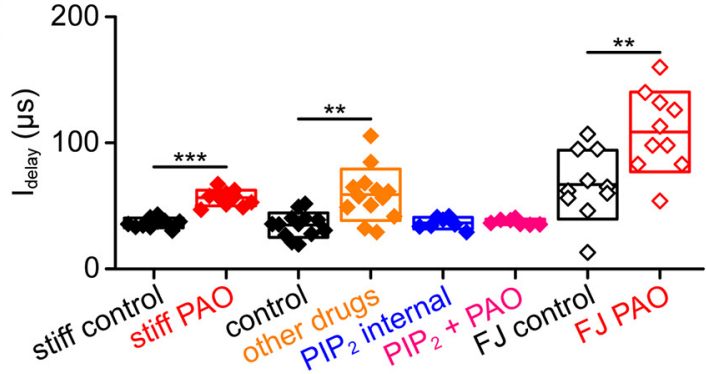

F

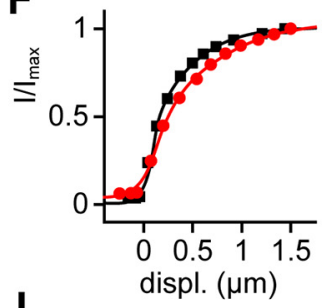

G

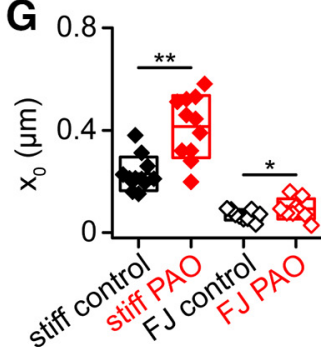

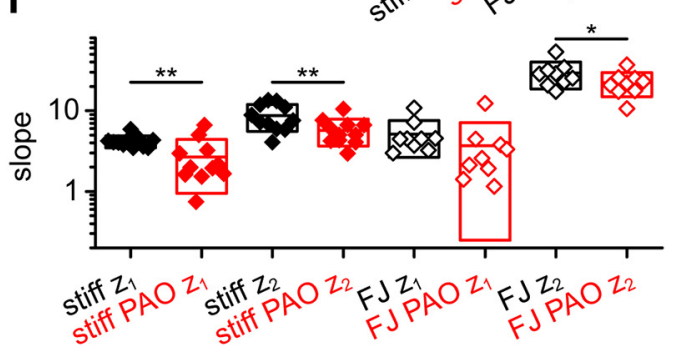

Figure 6. PAO treatment does not affect bundle compliance but MET-channel kinetics. $A$, Hair-bundle displacements during fluid-jet stimulation before (black) and after PAO (red) treatment. The displacements appear to be the same. $\boldsymbol{B}$, Maximal displacements for a given stimulus intensity after PA0 treatment ( $y$-axis) plotted against the control displacement for the same stimulus ( $x$-axis). The linear fit is forced through 0 and shows a slope of $0.98 \pm 0.02$ with a $R^{2}$ of 0.9 , suggesting that the hair-bundle displacement did not significantly change in the tested cells. Cyan triangles are measurements from A. C, MET-current example plots for displacements shown in $\boldsymbol{A}$. D. Expanded time axis on current onset, showing an increase in current delay and current rise time. $\boldsymbol{E}$, Summary plot of MET-current delay. PIP $_{2}$ manipulations increased the MET-current delay regardless of stimulus method. Intracellular $\mathrm{PIP}_{2}$ (blue) protected against the effect of PAO (purple). $\boldsymbol{F}$, Normalized current displacement (IX) plot for controls (black) and after PAO treatment (red). Lines represent a double Boltzmann fit of the data. $G$, Summary plot of the set point fit parameter, $X_{01}$, before (black) and after PAO (red) treatment. The parameter increased significantly regardless of stimulus method. $\boldsymbol{H}$, Summary plot of 10 of $90 \mathrm{MET}$-current rise times under different conditions. Treatment with PAO and other compounds significantly increases MET-current rise time, while intracellular PIP ${ }_{2}$ (blue) protects against the PA0 effect (purple). I, Both slopes $\left(z_{1}\right.$ and $\left.z_{2}\right)$ of stiff-probe-stimulated IX curves significantly decreased after PA0 treatment while only $z_{2}$ was significantly reduced during fluid-jet stimulation. Stiff probe, Closed symbols; fluid jet, open symbols. ${ }^{*} p<0.05$, ${ }^{* *} p<0.01$, ${ }^{* * *} p<0.001$. Boxes represent $S D$ and the line in the middle the mean.

time, indicating a tight coupling of force generation with channel activation (Ricci et al., 2005; Grillet et al., 2009; Stepanyan and Frolenkov, 2009). However, in response to a half-maximal stiffprobe stimulus, the MET-current rise time (Fig. $6 d, e$ ) increased significantly $(p=0.00023)$ from $42 \pm 16 \mu$ s in controls $(n=17)$ to $79 \pm 21 \mu \mathrm{s}$ after PAO treatment $(n=14$; Fig. $6 e)$ and from $58 \pm 15 \mu \mathrm{s}(n=12)$ to $95 \pm 12 \mu \mathrm{s}$ after treatment with other compounds $(n=12, p=0.00009)$, which were likely underestimated as control values are limited by probe speed. Fluid-jet stimulation has a slower rise time than stiff-probe stimulation, clearly underestimating true activation kinetics. Even so, METchannel activation slowed significantly from $0.6 \pm 0.1$ to $0.9 \pm$ $0.3 \mathrm{~ms}(n=10, p=0.012)$ after PAO treatment. Here too, intracellular $\mathrm{PIP}_{2}$ application protected against the $\mathrm{PAO}$ effect (rise times: before PAO treatment: $58 \pm 5 \mu \mathrm{s}$; after PAO treatment: $62 \pm 6 \mu \mathrm{s} ; n=7$, for stiff-probe stimulations, $p=0.09$ ). Altered activation kinetics may reflect a change in channel-stimulus coupling or a change in channel gating energy. The slowed activation kinetics were coupled to an increase in the MET-current delay relative to stimulus onset. Stiff-probe-stimulated MET-current delay increased significantly $\left(p=6.3 \times 10^{-7}\right)$ from $37 \pm 4$ to $56 \pm 6 \mu \mathrm{s}$ after PAO application (Fig. $6 h ; n=10$ ) and significantly from $33 \pm 9$ to $58 \pm 21 \mu$ s with the other tested compounds (Fig. $6 h ; p=0.0105, n=13$ ). Delays during fluid-jet stimulation increased from $67 \pm 26$ to $109 \pm 30 \mu$ s after PAO application (Fig. $6 h ; p<0.01, n=10$ ). Intracellular $\mathrm{PIP}_{2}$ protected against the effects of PAO (control: $36 \pm 4 \mu \mathrm{s} ; \mathrm{PAO}: 37 \pm$ $2 \mu s ; n=7, p=0.64$ ). Together, these data suggest that $\mathrm{PIP}_{2}$ is required for fast MET-channel activation, perhaps reflecting $\mathrm{PIP}_{2}$ modulation of single-channel gating force or a force relay element.

\section{Slight rightward shift and decreased steepness of current-displacement curves}

Current-displacement (IX) plots, fitted with a double Boltzmann equation (Eq. 1), provide a means of monitoring force transfer from bundle movement to channel opening. A change in the halfactivation position (set-point, $\mathrm{X}_{01}$ ) can indicate either a change in the resting hair-bundle tension or a change in the channel gating force. Similarly, a slope change $\left(z_{1}, z_{2}\right)$ can indicate a change in channel-gating energy or force transfer to the channel. As the 
A
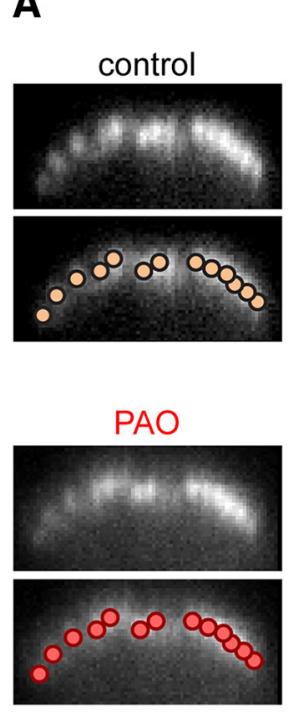

B

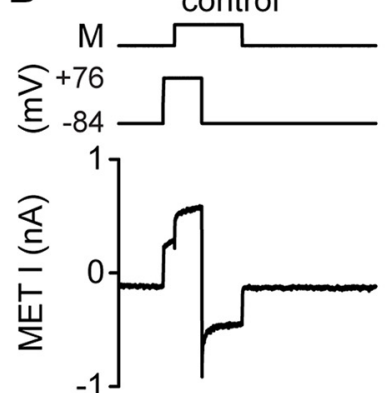

C
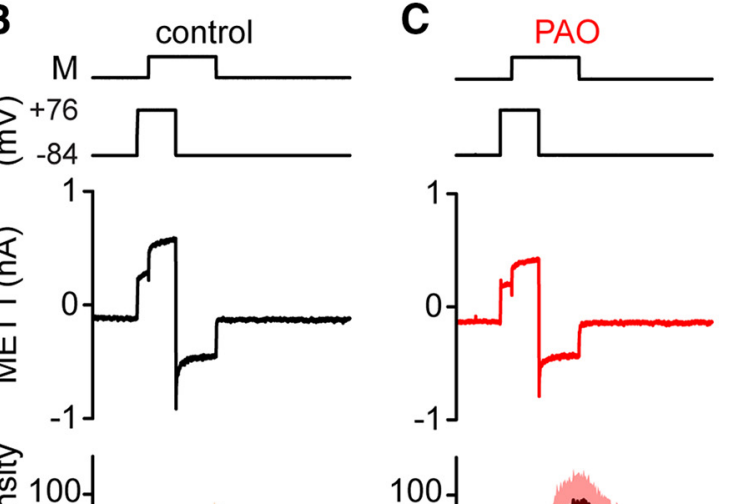

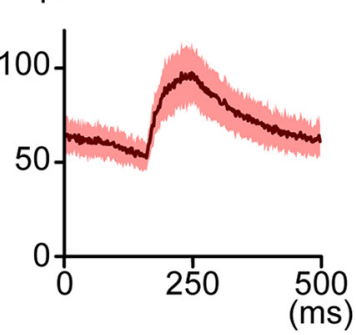

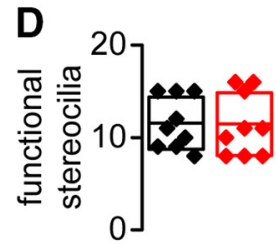

E

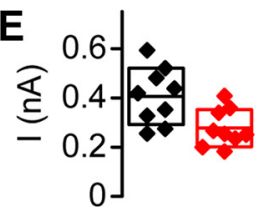

F

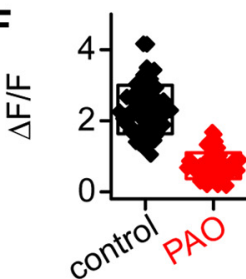

Figure 7. Calcium imaging reveals unaltered number of transducing stereocilia and reduction of $\mathrm{Ca}^{2+}$ inflow. $A$, Fluo-4FF fluorescent image of an IHC hair bundle, focused on the second row of stereocilia. Top two panels show the control image and selected ROI. The bottom two panels show the same hair bundle after 15 min of PAO application and the respective ROI. $\boldsymbol{B}$, Current and fluorescent intensity output from the cell shown in $A$ under control conditions. From top to bottom: (1) mechanical stimulus, (2) membrane holding potential, (3) current recording, (4) fluorescent change of control ROI (beige) and average of all ROI (black). C, Current and fluorescent intensity output from the cell shown in $\boldsymbol{A}$ and $\boldsymbol{B}$ after PAO treatment. $\boldsymbol{D}$, Summary plot of transducing stereocilia for all cells tested before and after PAO treatment. No significant change of stereocilia count was observed. $\boldsymbol{E}$, Summary plot of MET current measured in all tested cells before and after PAO treatment. The MET current was significantly reduced after PA0 treatment from $406 \pm 108 \mathrm{pA}(n=9)$ to $277 \pm 72 \mathrm{pA}(n=9)$. $\boldsymbol{F}$, Fluorescent intensity changes of individual stereocilia before $(2.3 \pm 0.7)$ and after PA0 treatment $(0.7 \pm 0.4) .{ }^{*} p<0.05,{ }^{* *} p<0.01,{ }^{* * *} p<0.001$. Boxes represent SD and the line in the middle the mean.

ability to close channels was compromised with $\mathrm{PIP}_{2}$ depletion, IX curves were assessed only based on the MET current that could be mechanically manipulated. Subsequent changes in set point and slope were evaluated (Fig. $6 f$ ). Both stiff-probe and fluid-jet data showed a small but significant ( stiff probe $p=0.0018$, fluid jet $p=0.0399$ ) rightward shift in the set-point after PAO treatment (Fig. $6 g$ ). They also showed a small but significant (stiff probe $p=0.0023$, fluid jet $p=0.041$ ) shallowing of the slope (Fig. 6i). These data suggest that either more force is required to open the channels or that the force relay to the channel is impaired after $\mathrm{PIP}_{2}$ depletion.

\section{Reduction of peak MET current is not due to loss of transducing stereocilia}

We used high-speed $\mathrm{Ca}^{2+}$ imaging to test whether the peak METcurrent reduction (Fig. 1c) after PAO treatment was due to a loss of transducing stereocilia or a reduction of current per stereocilium. We measured the fluorescence intensity of the $\mathrm{Ca}^{2+}$ indicator Fluo-4FF before and after PAO treatment as a proxy of $\mathrm{Ca}^{2+}$ inflow (Beurg et al., 2009). PAO treatment significantly increased the baseline fluorescence level from $18 \pm 11$ to $78 \pm 43$ (arbitrary units), which correlated with the increased resting current and was blocked by curare (Fig. 4e). During stimulation and simultaneous MET current recording, transducing stereocilia were identified by fluorescence-intensity changes (Fig. $5 b$ ). During control measurements, $12 \pm 3$ second-row stereocilia showed increased fluorescence intensity and the same count of second-row stereocilia remained transducing after PAO treatment $(12 \pm 3, n=9$; Fig. $7 d$ ). The MET current was $-406 \pm 108 \mathrm{pA}$ before and $-277 \pm 72$ pA after PAO treatment (Fig. 7e), which was deliberately nonsaturating to prevent stimulus-induced hair-bundle damage. Thus, there was no change in the number of functional stereocilia, despite the decrease in MET-current amplitude. The fluorescence change $(\Delta F / F)$ after PAO treatment was signifi- cantly reduced (Fig. $5 f$; from $2.3 \pm 0.7$ to $0.7 \pm 0.4, p=5 \times$ $10^{-17}$ ), indicating less $\mathrm{Ca}^{2+}$ entry per stereocilia after PAO treatment. Together, the data show that the peak MET current reduction is not due to loss of functional stereocilia and suggests a change in single-channel properties, such as $\mathrm{Ca}^{2+}$ permeability.

\section{Reduction of single-channel conductance}

We used $5 \mathrm{~mm}$ extracellular BAPTA to break tip links and measured remaining single-channel events, as previously described (Ricci et al., 2003; Beurg et al., 2006). Events were recorded at $-84 \mathrm{mV}$ and at $+76 \mathrm{mV}$ membrane holding potential before and after PAO treatment (Fig. 8) and normalized to the closed state. At $-84 \mathrm{mV}$, the single-channel current was significantly $(p=$ $0.00095)$ reduced from $-13.2 \pm 1.5 \mathrm{pA}(n=11$; Fig. $8 a)$ to $-8.3 \pm 1.2 \mathrm{pA}$ after PAO treatment $(n=8$; Fig. $8 b)$ and at +76 $\mathrm{mV}$ the single-channel current was significantly $(p=0.0011)$ reduced from $14 \pm 0.9 \mathrm{pA}(n=7$; Fig. $8 d)$ to $10.9 \pm 0.8 \mathrm{pA}(n=$ 4 ; Fig. $8 e$ ) after PAO treatment. The single-channel conductance was thus significantly $(p=0.00095)$ reduced from $157 \pm 18$ to $104 \pm 16 \mathrm{pS}$ at $-84 \mathrm{mV}$ and from $185 \pm 12$ to $143 \pm 10 \mathrm{pS}$ at +76 $\mathrm{mV}(p=0.0011)$ after PAO treatment (Fig. $8 c, f)$. This singlechannel current reduction of $34 \pm 8 \%(n=6)$ was comparable ( $p=0.94$ ) to the observed macroscopic peak MET-current reductions of $35 \pm 17 \%(n=22)$. Based on single-channel and peak MET current, we calculated the number of active channels to be $64 \pm 2$ in both control and PAO conditions, supporting the finding that the macroscopic MET peak-current reduction is based on the single-channel conductance reduction. Single-channel adaptation was observed in controls and after PAO treatment. Average single-channel events showed an adaptation extent of $44 \pm$ $16 \%$ at $-84 \mathrm{mV}$ and $35 \pm 18 \%$ at $+76 \mathrm{mV}$ holding potential. $\mathrm{PAO}$ treatment significantly reduced the adaptation extent to $17 \pm 7 \%$ at $-84 \mathrm{mV}(p=0.00015)$ and $8 \pm 4 \%$ at $+76 \mathrm{mV}(p=$ 
A

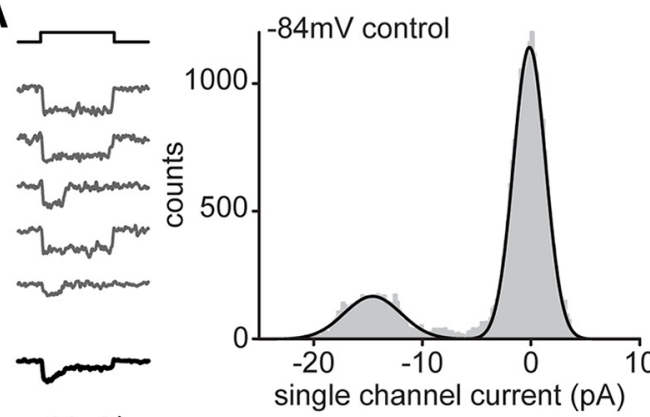

$20 \mathrm{pAl}$

$5 \overline{0 \mathrm{~ms}}$

D

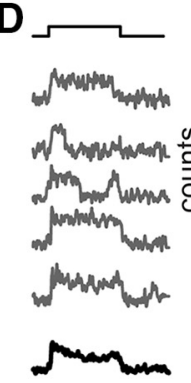

B

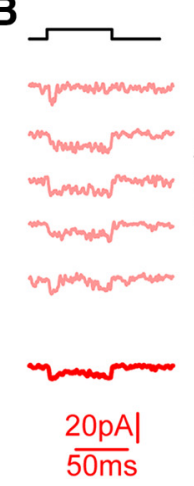

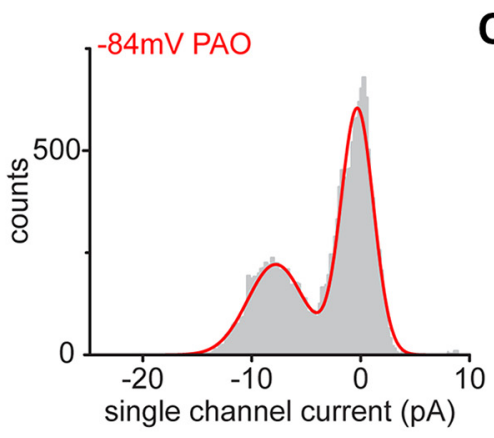

E.

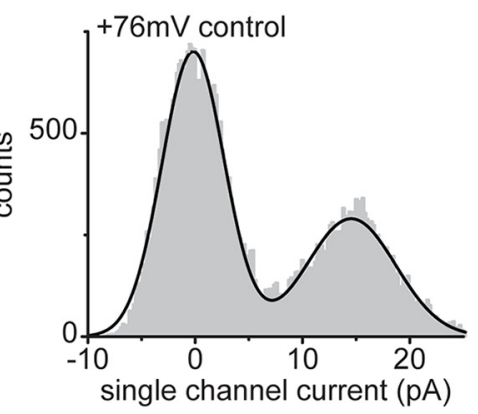

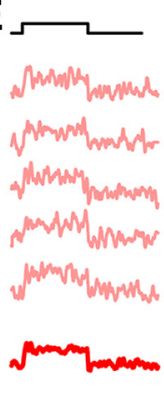

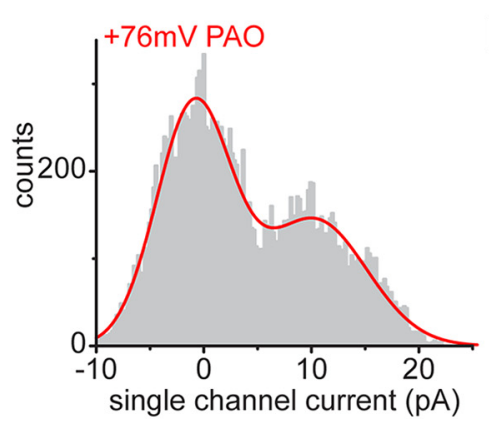

C

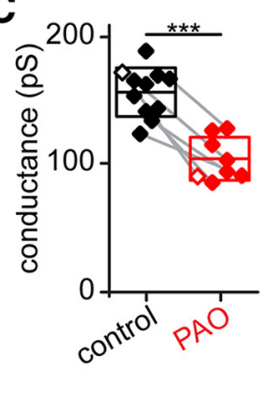

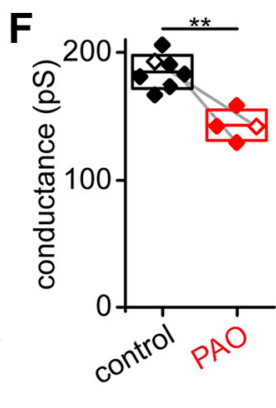

Figure 8. Single-channel conductance measurements before and after PA0 treatment at negative and positive holding potentials. $\boldsymbol{A}$, Five examples (gray) of single-channel gating events at $-84 \mathrm{mV}$ holding potential on the left top and an average below (black). The histogram on the right shows a summation of individual events where zero equals their average prestimulus baseline. The black line represents a Gaussian fit with two peaks, a closed state $(0.1 \pm 0.012 \mathrm{pA})$ and an open state $(14.6 \pm 0.1 \mathrm{pA})$. B, Five examples of single-channel events at $-84 \mathrm{mV}$ holding potential after $20 \mathrm{~min}$ PAO treatment on the left and an average below. The red line represents a Gaussian fit with two peaks, an open state ( $7.8 \pm 0.1 \mathrm{pA})$ and a closed state ( $0.26 \pm 0.04 \mathrm{pA}) . \boldsymbol{C}, \mathrm{Summary}$ plot of single-channel conductance at $-84 \mathrm{mV}$ holding potential for controls and PA0-treated cells. Average single-channel conductance was significantly reduced from $157 \pm 18 \mathrm{pS}$ in controls $(n=11)$ to $104 \pm 16 \mathrm{pS}$ after PA0 treatment $(n=8)$. Gray lines connect paired cells $(n=6)$. $D$, Five examples of single-channel events at $+76 \mathrm{mV}$ holding potential shown on left and an average below. The black line represents a Gaussian fit with two peaks, an open state $(14 \pm 1 \mathrm{pA})$ and a closed state $(0.2 \pm 0.03 \mathrm{pA})$. $\boldsymbol{E}$, Five examples of single-channel events at $+76 \mathrm{mV}$ holding potential after $20 \mathrm{~min}$ of PAO treatment on the left and an average below. The red line represents a Gaussian fit with two peaks, an open state (10.1 $\pm 0.3 \mathrm{pA})$ and a closed state (1.1 $\pm 0.1 \mathrm{pA}) . \boldsymbol{F}$, Summary plot of single-channel conductance at $+76 \mathrm{mV}$ holding potential for control and PA0-treated cells. Average single-channel conductance was $185 \pm 12 \mathrm{pS}$ for control cells ( $n=7$ ) and $143 \pm 10 \mathrm{pS}$ for PA0-treated cells $(n=4)$, which was significantly different ( $p=0.001)$. Gray lines connect paired cells $(n=2)$. Histograms show a summation of individual events where zero equals their average prestimulus baseline. Open symbols represent example cells shown in $\boldsymbol{A}, \boldsymbol{B}, \boldsymbol{D}$, and $\boldsymbol{E}$. ${ }^{*} p<0.05,{ }^{* *} p<0.01,{ }^{* * *} p<0.001$. Boxes represent $S D$ and the line in the middle the mean.

$0.0025)$ respectively, which is comparable to the observed macroscopic MET-current effects on dynamic adaptation.

\section{Reduced $\mathrm{Ca}^{2+}$ block strength after $\mathrm{PIP}_{2}$ depletion/block}

$\mathrm{Ca}^{2+}$ permeates and blocks the MET channel (Crawford et al., 1991; Ricci and Fettiplace, 1998; Pan et al., 2012). Lowering the external $\mathrm{Ca}^{2+}$ to $25 \mu \mathrm{M}\left(\mathrm{Ca}^{2+}\right.$ being the only divalent ion) relieves the $\mathrm{Ca}^{2+}$ block and increases the peak MET current at -84 $\mathrm{mV}$ holding potential by $200 \pm 39 \%$ relative to control conditions (divalent ions: $2 \mathrm{mM} \mathrm{Ca}^{2+}$ and $1 \mathrm{mM} \mathrm{Mg}^{2+}$; Fig. $7 a-c$ ). After PAO treatment, the increase in peak current was reduced to $129 \pm 16 \%$ relative to PAO-treated cells in control conditions. This suggests that $\mathrm{PIP}_{2}$ depletion either decreases the $\mathrm{Ca}^{2+}$ dependent block of the MET current (Crawford et al., 1991) at $2 \mathrm{mM}$ external $\mathrm{Ca}^{2+}$ concentration or strengthens the block at $25 \mu \mathrm{M} \mathrm{ex}-$ ternal $\mathrm{Ca}^{2+}$ levels.

The MET-current reversal potential gives indication about MET-channel ion selectivity (Ohmori, 1985; Fettiplace, 2009). We calculated the reversal potential based on a single-site blocking model (Eq. 3) as described previously (Rüsch et al., 1994; Farris et al., 2004; Fig. 9d,e). The fit parameters $k$ (proportionality constant) and $V_{\mathrm{s}}$ (steepness of rectification) were not significantly affected. $V_{\mathrm{r}}$ (reversal potential) changed significantly from $4.7 \pm 0.5 \mathrm{mV}$ in controls to $-4.3 \pm 3.5 \mathrm{mV}(n=7, p=0.0007)$ after PAO treatment (Fig. $9 f$ ), suggesting a change in ion selectivity. $\delta$ (Fractional distance through the electric field of mem- brane) shifted significantly ( $p=0.0016)$ further through the membrane's electrical field toward the intracellular side from a fractional distance of $42 \pm 2 \%$ in controls to $48 \pm 2 \%$ after PAO treatment (Fig. 9g). Together the effects on $\mathrm{Ca}^{2+}$ inflow (Fig. $7 f$ ), single-channel conductance (Fig. $8 c, f$ ), $\mathrm{Ca}^{2+}$-dependent block, and reversal potential (Fig. 9f) suggest that the channel pore was less permeable for $\mathrm{Ca}^{2+}$ when $\mathrm{PIP}_{2}$ was depleted.

\section{Discussion}

Although $\mathrm{PIP}_{2}$ is known to modulate other mechanosensitive channels (Chemin et al., 2007a,b; Anishkin et al., 2014; Brohawn et al., 2014; Rasmussen, 2016) and has been shown to affect MET in isolated bullfrog sacculus hair cells (Hirono et al., 2004), PIP 's specific role and mode of action in mammalian auditory hair-cell mechanotransduction was not determined.

Hirono et al. (2004) found that after $\mathrm{PIP}_{2}$ depletion, the open probability increased, while the MET-current peak amplitude and adaptation were reduced. We found similar results for the METcurrent peak amplitude reduction, open probability change, and effects on adaptation. This similarity in basic responses would suggest similarity in the underlying mode of action. Our data show that the MET-channel population responsible for the increase in open probability was mechanically insensitive, while in isolated bullfrog sacculus hair cells, negative stimulation was able to close most MET channels (Hirono et al., 2004). This difference may be inherent to differences in hair-bundle cohesion instead of mechanistic differ- 

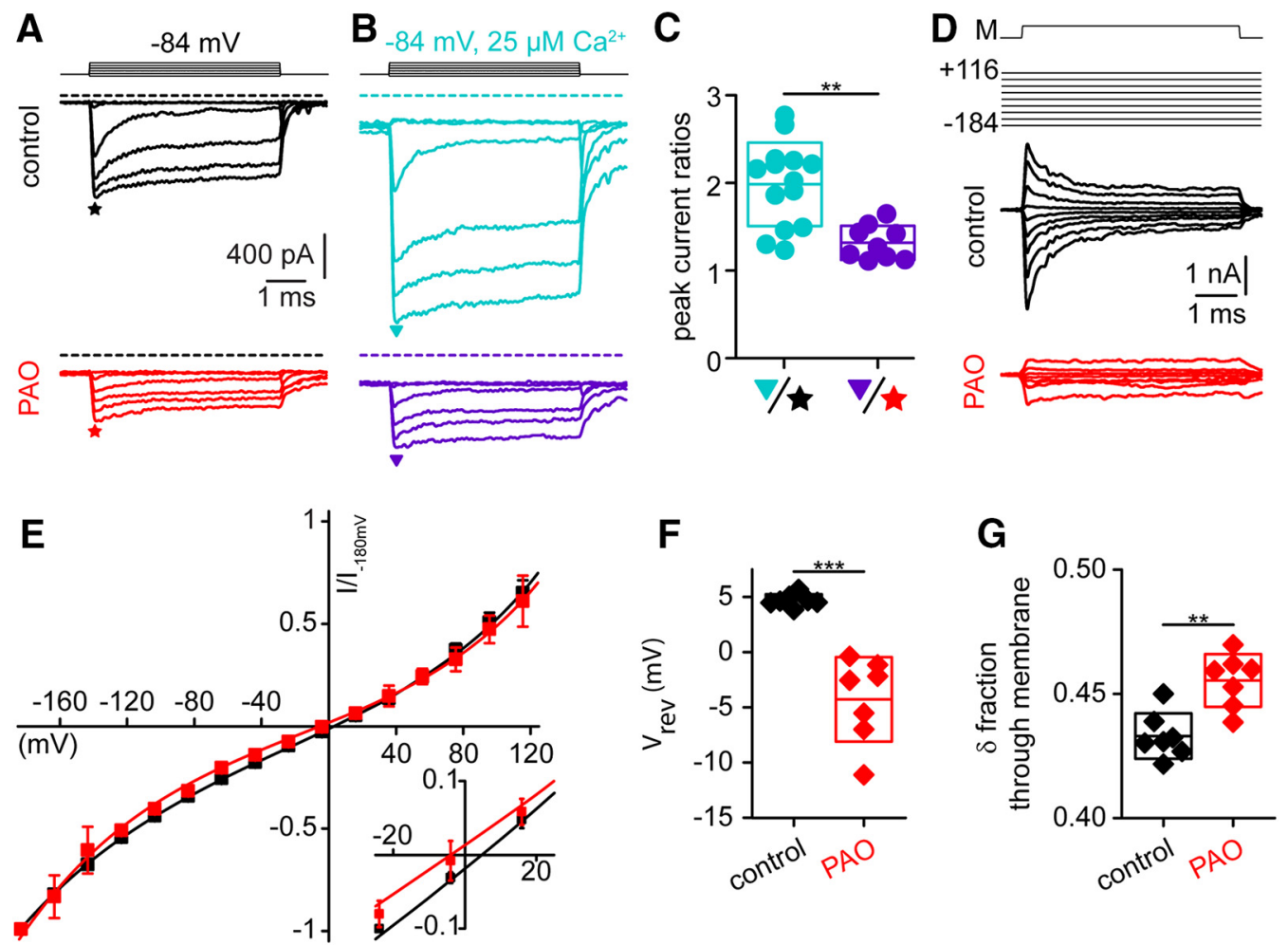

Figure 9. Lowering external $\mathrm{Ca}^{2+}$ affects MET currents less after PAO treatment and the reversal potential shifts from positive to negative values. $A$, MET-current response before (black) and after PA0 treatment (red) at $-84 \mathrm{mV}$ holding potential. The star symbols mark peak current and relate to $C$. $B$, MET-current response in $25 \mu \mathrm{m}$ external $\mathrm{Ca}^{2+}$ before (teal) and after PA0 treatment (violet) at $-84 \mathrm{mV}$ holding potential. Upside-down triangle symbols mark peak current and relate to C.C, Current ratios in different conditions before and after PA0 treatment. Application of $25 \mu \mathrm{m}$ extracellular $\mathrm{Ca}^{2+}$ relieves the partial $\mathrm{Ca}^{2+}$ block, leading to a current increase of $200 \pm 36 \%$ (teal circles, $n=14$ ), which is reduced to $129 \pm 16 \%$ (violet, $n=9$ ) after PA0 treatment. $\boldsymbol{D}$, Current recordings of control (black) and PA0-treated (red) cells for IXIV experiments, where the hair bundle was mechanically stimulated (M) while stepping to different membrane holding potentials from -184 to $+116 \mathrm{mV}$ ( $40 \mathrm{mV}$ increments are shown). $\boldsymbol{E}$, Averaged and normalized MET-current response at different membrane holding potentials ( $-184 \mathrm{to}+116 \mathrm{mV}, 20 \mathrm{mV}$ increments) of control (black, $n=7$ ) and PA0-treated cells. A single-site binding model was used to fit the data. Inset shows a zoom-in between -25 and $+25 \mathrm{mV}$ holding potential. $\boldsymbol{F}$, Average reversal potential was significantly changed from $4.7 \pm 0.5 \mathrm{mV}$ in controls to $-4.3 \pm 3.5 \mathrm{mV}$ after PA0 treatment $(n=7)$. G, The fractional distance $(\delta)$ of the blocking site through the membrane electric field was significantly $(p=0.0016)$ increased from $42 \pm 2 \%$ in controls to $48 \pm 2 \%$ after PAO $(n=7) .{ }^{*} p<0.05,{ }^{* *} p<0.01,{ }^{* * *} p<0.001$. Boxes represent SD and the line in the middle the mean.

ence in $\operatorname{PIP}_{2}$ action (Langer et al., 2001; Karavitaki and Corey, 2010; Nam et al., 2015).

We expanded on the work by Hirono et al. (2004) demonstrating that MET-channel pore properties are altered after PIP $_{2}$ depletion. These changes in permeation and conductance underlie the observed MET-current peak amplitude reduction.

Hirono et al. (2004) suggested that the loss of interaction between $\mathrm{PIP}_{2}$ and Myo1C was responsible for the observed effects after PIP ${ }_{2}$ depletion. This seems unlikely in mammalian IHCs for several reasons. First, a myosin-based adaptation process is likely too slow. Second, fast adaptation is $\mathrm{Ca}^{2+}$ independent (Peng et al., 2013). Third, channel location at the lower end of the tip link makes it difficult for myosin at the upper insertion site to be modulated by the MET channel (Peng et al., 2011). Fourth, there is a reduced contribution of the slower component of adaptation in mammalian cochlear hair cells when a stiff probe is used, suggesting that even if a motor component is involved, it likely will manifest with the properties described herein. However, neither dataset provides direct evidence for the underlying mechanism of fast adaptation; the data only support the idea that PIP $_{2}$ modulates this process in both systems. Also, we have not specifically characterized slower components of adaptation that might be regulated by myosin and PIP $_{2}$.

Data presented in this manuscript suggest a direct role for $\mathrm{PIP}_{2}$ in modulating MET-channel pore properties and in the manifestation of fast adaptation, rather than an indirect effect through Myo1C (Hirono et al., 2004). Other channels require $\mathrm{PIP}_{2}$ to enable them to become active and perform their function (Tang et al., 2014; Kim et al., 2015; Lee et al., 2016). That PIP constitutes $\sim 1.5 \%$ of the lipids in the chicken hair bundle (Zhao et al., 2012) further supports a direct action at a protein in the mechanotransduction complex rather than an indirect effect through changes in membrane curvature or organization.

\section{Adaptation and $P_{O}$ are not exclusively linked}

Recent data showed that MET channel $\mathrm{P}_{\mathrm{O}}$ can be independently modulated by extracellular divalent ion manipulations, while MET-current adaptation remained largely unaltered (Peng et al., 2016). The hypothesis suggested that divalent ions alter lipid packing, which in turn alters the energy required to gate MET channels. We show here a significant reduction of MET-current adaptation with a comparably small effect on $\mathrm{P}_{\mathrm{O}}$, additionally supporting the conclusion that adaptation and $\mathrm{P}_{\mathrm{O}}$ are modulated independently. These data also suggest that $\mathrm{PIP}_{2}$ does not underlie the previously described global lipid packing effect. Additionally, PIP $_{2}$ is predominantly localized in the intracellular membrane leaflet, its effector site is thus likely found intracellularly, possibly associated with the MET complex.

\section{A fast, PIP $_{2}$-dependent component of adaptation}

A hallmark of the auditory MET channel is adaptation: where during constant stimulation the MET current amplitude de- 
creases but recovers with increased stimulus intensity. While a double exponential fit $\left(\tau_{1}\right.$ and $\left.\tau_{2}\right)$ is required in controls, a single exponential fit (similar to $\tau_{2}$ ) is sufficient after PAO treatment. The observed MET-current adaptation effect is further supported by single-channel measurements that showed a reduction of adaptation extent after $\mathrm{PIP}_{2}$ depletion. How $\mathrm{PIP}_{2}$ affects adaptation and the underlying process remains unknown and further investigation is necessary. One possible explanation could be a repacking of $\mathrm{PIP}_{2}$ in the intracellular leaflet that is induced by mechanical stress in the membrane (Li et al., 2011; Yang et al., 2015; Petersen et al., 2016), such as the pull from the tip link, resulting in reduced force relay and subsequent MET-channel closure.

\section{Possible PIP $_{2}$ interactions}

Obvious $\mathrm{PIP}_{2}$-binding motifs were not found in proteins generally implicated in the MET complex P10 and older), such as TMC1 (Pan et al., 2013; Kurima et al., 2015), TMIE (Yang et al., 2010; Zhao et al., 2014), or LHFPL5 (Xiong et al., 2012; Beurg et al., 2015). However, PIP $_{2}$-binding domains can involve residues from different transmembrane domains or even separate channel subunits (McLaughlin et al., 2002; Hansen et al., 2011). This renders predictions about $\mathrm{PIP}_{2}$-binding sites difficult without knowledge of appropriate tertiary and quaternary structures, as well as stoichiometry of the involved proteins. Independent of possible interaction partners and based on our data, we can speculate on how $\mathrm{PIP}_{2}$ affects MET channels. Known channel-PIP interactions, such as between $\mathrm{PIP}_{2}$ and Kir2.2 (Hansen et al., 2011; Lee et al., 2016), suggest that $\mathrm{PIP}_{2}$ is required for a correct tertiary and quaternary structure of the MET channel that could affect the channel pore. Our data also suggest a change in $\mathrm{Ca}^{2+}$ permeability of the MET channel. The supporting results for this are as follows: (1) a reduction of $\mathrm{Ca}^{2+}$ inflow after PAO treatment (Fig. 5f), (2) a reduction of the relief of the $\mathrm{Ca}^{2+}$ block at 25 $\mu \mathrm{M}$ extracellular $\mathrm{Ca}^{2+}$ concentration (Fig. $7 c$ ), and (3) a negative shift of the reversal potential (Fig. $7 f$ ). While the negative reversal potential shift could also be explained by a reduction of $\mathrm{Na}^{+}$ permeability, the $\mathrm{Ca}^{2+}$ imaging and relief of block data directly support a change in $\mathrm{Ca}^{2+}$ permeability.

Previous work showed that a negative reversal potential shift is observed when less $\mathrm{Ca}^{2+}$ permeates the channel (Ohmori, 1985). Other data also showed that $\mathrm{Ca}^{2+}$ carries a large portion of the total MET current and modulates the permeability for monovalent ions (Ohmori, 1985; Ricci and Fettiplace, 1998), which would be sufficient to explain single-channel conductance and peak-current reduction.

One can also speculate that effects on the pore structure might alter channel-gating energies that affect channel-state transitions, which could explain the population of mechanically insensitive channels that are open at rest and the effects on current-displacement relationship. Alterations of the vestibule, changing the electrical driving force from the extracellular side, might explain the conductance changes but not the relief of $\mathrm{Ca}^{2+}$ block or reversal potential effects. Effects on adaptation cannot be explained easily, as the structures involved with adaptation and how adaptation works remain unknown. The effects on channel-activation kinetics are insufficient to explain the effects on adaptation, as channelactivation kinetics and channel-adaptation kinetics are likely $>1$ order of magnitude apart. Assuming that fast adaptation maintains a certain tension on the MET channel, a loss of said tension could slow MET-channel activation. However, it is plausible to suggest that fast adaptation is intrinsic to the MET complex's quaternary structure.

\section{Possible PIP $_{2}$ mode of action on MET machinery}

The dramatic reduction of $\mathrm{PIP}_{2}$ from the stereocilia in 10-20 min, when blocking its synthesis, indicates a high turnover rate and regulation of $\mathrm{PIP}_{2}$, as previously reported, in stereocilia (Hirono et al., 2004) with an as-yet-unknown function; however, this high turnover rate provides a means to investigate $\mathrm{PIP}_{2}$ function. The strength of the MET-current effects correlated with the strength of $\mathrm{PIP}_{2}$ labeling, arguing for a critical minimal amount of $\mathrm{PIP}_{2}$ in the membrane for normal MET-channel function (Fig. $2 d-f$ ). Intracellular $\mathrm{PIP}_{2}$ application protected against $\mathrm{PAO}$ treatment while not altering MET-current properties, arguing for $\mathrm{PIP}_{2}$ specificity and saturation of its functional site under normal conditions. Interestingly, the single-channel effects we found are generally attributed to changes of the MET machinery and are regularly used to argue for or against a protein's function as the MET channel. While we are not suggesting that $\mathrm{PIP}_{2}$ is the MET channel, manipulations of $\mathrm{PIP}_{2}$ are sufficient to affect single-channel properties and $\mathrm{Ca}^{2+}$ permeation, questioning the validity of these properties as tools for identifying the molecular channel components. $\mathrm{PIP}_{2}$ now joins the ranks of such molecules as TMC1/2 (Pan et al., 2013; Kurima et al., 2015), TMIE (Zhao et al., 2014), and LHFPL5 (Xiong et al., 2012), which can alter what had previously been considered intrinsic channel properties.

In conclusion, our data show that $\mathrm{PIP}_{2}$ is likely a METchannel cofactor directly interacting with the MET-channel complex, modulating a fast component of adaptation, and affecting MET-channel pore properties.

\section{References}

Abderemane-Ali F, Es-Salah-Lamoureux Z, Delemotte L, Kasimova MA, Labro AJ, Snyders DJ, Fedida D, Tarek M, Baró I, Loussouarn G (2012) Dual effect of phosphatidylinositol (4,5)-bisphosphate PIP(2) on Shaker $\mathrm{K}(+)$ [corrected] channels. J Biol Chem 287:36158-36167. CrossRef Medline

Anishkin A, Loukin SH, Teng J, Kung C (2014) Feeling the hidden mechanical forces in lipid bilayer is an original sense. Proc Natl Acad Sci U S A 111:7898-7905. CrossRef Medline

Bavi O, Vossoughi M, Naghdabadi R, Jamali Y (2016) The combined effect of hydrophobic mismatch and bilayer local bending on the regulation of mechanosensitive ion channels. PLoS One 11:e0150578. CrossRef Medline

Beurg M, Evans MG, Hackney CM, Fettiplace R (2006) A large-conductance calcium-selective mechanotransducer channel in mammalian cochlear hair cells. J Neurosci 26:10992-11000. CrossRef Medline

Beurg M, Fettiplace R, Nam JH, Ricci AJ (2009) Localization of inner hair cell mechanotransducer channels using high-speed calcium imaging. Nat Neurosci 12:553-558. CrossRef Medline

Beurg M, Xiong W, Zhao B, Müller U, Fettiplace R (2015) Subunit determination of the conductance of hair-cell mechanotransducer channels. Proc Natl Acad Sci U S A 112:1589-1594. CrossRef Medline

Brohawn SG, Campbell EB, MacKinnon R (2014) Physical mechanism for gating and mechanosensitivity of the human TRAAK K+ channel. Nature 516:126-130. CrossRef Medline

Chemin J, Patel AJ, Duprat F, Sachs F, Lazdunski M, Honore E (2007a) Upand down-regulation of the mechano-gated K(2P) channel TREK-1 by PIP (2) and other membrane phospholipids. Pflugers Arch 455:97-103. CrossRef Medline

Chemin J, Patel AJ, Delmas P, Sachs F, Lazdunski M, Honore E (2007b) Regulation of the mechano-gated K2P channel TREK-1 by membrane phospholipids. Curr Top Membr 59:155-170. CrossRef Medline

Corns LF, Johnson SL, Kros CJ, Marcotti W (2014) Calcium entry into stereocilia drives adaptation of the mechanoelectrical transducer current of mammalian cochlear hair cells. Proc Natl Acad Sci U S A 111:1491814923. CrossRef Medline

Crawford AC, Evans MG, Fettiplace R (1991) The actions of calcium on the mechano-electrical transducer current of turtle hair cells. J Physiol 434: 369-398. CrossRef Medline

Engel A, Gaub HE (2008) Structure and mechanics of membrane proteins. Annu Rev Biochem 77:127-148. CrossRef Medline 
Farris HE, LeBlanc CL, Goswami J, Ricci AJ (2004) Probing the pore of the auditory hair cell mechanotransducer channel in turtle. J Physiol 558: 769-792. CrossRef Medline

Fettiplace R (2009) Defining features of the hair cell mechanoelectrical transducer channel. Pflugers Arch 458:1115-1123. CrossRef Medline

Glowatzki E, Ruppersberg JP, Zenner HP, Rüsch A (1997) Mechanically and ATP-induced currents of mouse outer hair cells are independent and differentially blocked by d-tubocurarine. Neuropharmacology 36:12691275. CrossRef Medline

Goodyear RJ, Gale JE, Ranatunga KM, Kros CJ, Richardson GP (2008a) Aminoglycoside-induced phosphatidylserine externalization in sensory hair cells is regionally restricted, rapid, and reversible. J Neurosci 28 : 9939-9952. CrossRef Medline

Grillet N, Xiong W, Reynolds A, Kazmierczak P, Sato T, Lillo C, Dumont RA, Hintermann E, Sczaniecka A, Schwander M, Williams D, Kachar B, Gillespie PG, Müller U (2009) Harmonin mutations cause mechanotransduction defects in cochlear hair cells. Neuron 62:375-387. CrossRef Medline

Hansen SB (2015) Lipid agonism: the $\mathrm{PIP}_{2}$ paradigm of ligand-gated ion channels. Biochim Biophys Acta 1851:620-628. CrossRef Medline

Hansen SB, Tao X, MacKinnon R (2011) Structural basis of PIP $_{2}$ activation of the classical inward rectifier K+ channel Kir2.2. Nature 477:495-498. CrossRef Medline

Hardie RC, Franze K (2012) Photomechanical responses in Drosophila photoreceptors. Science 338:260-263. CrossRef Medline

Hille B, Dickson EJ, Kruse M, Vivas O, Suh BC (2015) Phosphoinositides regulate ion channels. Biochim Biophys Acta 1851:844-856. CrossRef Medline

Hirono M, Denis CS, Richardson GP, Gillespie PG (2004) Hair cells require phosphatidylinositol 4,5-bisphosphate for mechanical transduction and adaptation. Neuron 44:309-320. CrossRef Medline

Hudspeth AJ (2005) How the ear's works work: mechanoelectrical transduction and amplification by hair cells. Comptes Rendus Biologies 328: 155-162. CrossRef Medline

Hurst AC, Gottlieb PA, Martinac B (2009) Concentration dependent effect of GsMTx4 on mechanosensitive channels of small conductance in E. coli spheroplasts. Eur Biophys J 38:415-425. CrossRef Medline

Kachar B, Parakkal M, Kurc M, Zhao Y, Gillespie PG (2000) High-resolution structure of hair-cell tip links. Proc Natl Acad Sci U S A 97:13336-13341. CrossRef Medline

Karavitaki KD, Corey DP (2010) Sliding adhesion confers coherent motion to hair cell stereocilia and parallel gating to transduction channels. J Neurosci 30:9051-9063. CrossRef Medline

Kazmierczak P, Sakaguchi H, Tokita J, Wilson-Kubalek EM, Milligan RA, Müller U, Kachar B (2007) Cadherin 23 and protocadherin 15 interact to form tip-link filaments in sensory hair cells. Nature 449:87-91. CrossRef Medline

Kim DI, Kang M, Kim S, Lee J, Park Y, Chang I, Suh BC (2015) Molecular basis of the membrane interaction of the $\beta 2$ e subunit of voltage-gated $\mathrm{Ca}(2+)$ channels. Biophys J 109:922-935. CrossRef Medline

Kim J, Pinsky PM, Ricci AJ, Puria S, Steele CR (2011) Elastostatic analysis of the membrane tenting deformation of inner-ear stereocilia. AIP Conf Proc 1403:50-52. CrossRef

Kros CJ, Rüsch A, Richardson GP (1992) Mechano-electrical transducer currents in hair cells of the cultured neonatal mouse cochlea. Proc Biol Sci 249:185-193. CrossRef Medline

Kruse M, Hille B (2013) The phosphoinositide sensitivity of the K(v) channel family. Channels (Austin) 7:530-536. CrossRef Medline

Kurima K, Ebrahim S, Pan B, Sedlacek M, Sengupta P, Millis BA, Cui R, Nakanishi H, Fujikawa T, Kawashima Y, Choi BY, Monahan K, Holt JR, Griffith AJ, Kachar B (2015a) TMC1 and TMC2 localize at the site of mechanotransduction in mammalian inner ear hair cell stereocilia. Cell Rep 12:1606-1617. CrossRef Medline

Langer MG, Fink S, Koitschev A, Rexhausen U, Hörber JK, Ruppersberg JP (2001) Lateral mechanical coupling of stereocilia in cochlear hair bundles. Biophys J 80:2608-2621. CrossRef Medline

Lee SJ, Ren F, Zangerl-Plessl EM, Heyman S, Stary-Weinzinger A, Yuan P, Nichols CG (2016) Structural basis of control of inward rectifier Kir2 channel gating by bulk anionic phospholipids. J Gen Physiol 148:227237. CrossRef Medline

Li X, Wang X, Yang Y, Li R, He Q, Fang X, Luu DT, Maurel C, Lin J (2011) Single-molecule analysis of $\mathrm{PIP}_{2} ; 1$ dynamics and partitioning reveals multiple modes of Arabidopsis plasma membrane aquaporin regulation. Plant Cell 23:3780-3797. CrossRef Medline

Malcolm HR, Blount P, Maurer JA (2015) The mechanosensitive channel of small conductance (MscS) functions as a jack-in-the-box. Biochim Biophys Acta 1848:159-166. CrossRef Medline

McLaughlin S, Wang J, Gambhir A, Murray D (2002) PIP(2) and proteins: interactions, organization, and information flow. Annu Rev Biophys Biomol Struct 31:151-175. CrossRef Medline

Meyer J, Furness DN, Zenner HP, Hackney CM, Gummer AW (1998) Evidence for opening of hair-cell transducer channels after tip-link loss. J Neurosci 18:6748-6756. Medline

Meyer J, Preyer S, Hofmann SI, Gummer AW (2005) Tonic mechanosensitivity of outer hair cells after loss of tip links. Hear Res 202:97-113. CrossRef Medline

Nam JH, Peng AW, Ricci AJ (2015) Underestimated sensitivity of mammalian cochlear hair cells due to splay between stereociliary columns. Biophys J 108:2633-2647. CrossRef Medline

Ohmori H (1985) Mechano-electrical transduction currents in isolated vestibular hair cells of the chick. J Physiol 359:189-217. CrossRef Medline

Pan B, Waguespack J, Schnee ME, LeBlanc C, Ricci AJ (2012) Permeation properties of the hair cell mechanotransducer channel provide insight into its molecular structure. J Neurophysiol 107:2408-2420. CrossRef Medline

Pan B, Géléoc GS, Asai Y, Horwitz GC, Kurima K, Ishikawa K, Kawashima Y, Griffith AJ, Holt JR (2013) TMC1 and TMC2 are components of the mechanotransduction channel in hair cells of the mammalian inner ear. Neuron 79:504-515. CrossRef Medline

Patel AJ, Lazdunski M, HonoréE (2001) Lipid and mechano-gated 2P domain $\mathrm{K}(+)$ channels. Curr Opin Cell Biol 13:422-428. CrossRef Medline

Peng AW, Salles FT, Pan B, Ricci AJ (2011) Integrating the biophysical and molecular mechanisms of auditory hair cell mechanotransduction. Nat Commun 2:523. CrossRef Medline

Peng AW, Effertz T, Ricci AJ (2013) Adaptation of mammalian auditory hair cell mechanotransduction is independent of calcium entry. Neuron 80:960-972. CrossRef Medline

Peng AW, Gnanasambandam R, Sachs F, Ricci AJ (2016) Adaptation independent modulation of auditory hair cell mechanotransduction channel open probability implicates a role for the lipid bilayer. J Neurosci 36: 2945-2956. CrossRef Medline

Petersen EN, Chung HW, Nayebosadri A, Hansen SB (2016) Kinetic disruption of lipid rafts is a mechanosensor for phospholipase D. Nat Commun 7:13873. CrossRef Medline

Phillips KR, Tong S, Goodyear R, Richardson GP, Cyr JL (2006) Stereociliary myosin- $1 \mathrm{c}$ receptors are sensitive to calcium chelation and absent from cadherin 23 mutant mice. J Neurosci 26:10777-10788. CrossRef Medline

Pickles JO, Comis SD, Osborne MP (1984) Cross-links between stereocilia in the guinea pig organ of Corti, and their possible relation to sensory transduction. Hear Res 15:103-112. CrossRef Medline

Pliotas C, Dahl AC, Rasmussen T, Mahendran KR, Smith TK, Marius P, Gault J, Banda T, Rasmussen A, Miller S, Robinson CV, Bayley H, Sansom MS, Booth IR, Naismith JH (2015) The role of lipids in mechanosensation. Nat Struct Mol Biol 22:991-998. CrossRef Medline

Powers RJ, Kulason S, Atilgan E, Brownell WE, Sun SX, Barr-Gillespie PG, Spector AA (2014) The local forces acting on the mechanotransduction channel in hair cell stereocilia. Biophys J 106:2519-2528. CrossRef Medline

Rasmussen T (2016) How do mechanosensitive channels sense membrane tension? Biochem Soc Trans 44:1019-1025. CrossRef Medline

Ricci AJ, Fettiplace R (1998) Calcium permeation of the turtle hair cell mechanotransducer channel and its relation to the composition of endolymph. J Physiol 506:159-173. CrossRef Medline

Ricci AJ, Crawford AC, Fettiplace R (2003) Tonotopic variation in the conductance of the hair cell mechanotransducer channel. Neuron 40:983990. CrossRef Medline

Ricci AJ, Kennedy HJ, Crawford AC, Fettiplace R (2005) The transduction channel filter in auditory hair cells. J Neurosci 25:7831-7839. CrossRef Medline

Rüsch A, Kros CJ, Richardson GP (1994) Block by amiloride and its derivatives of mechano-electrical transduction in outer hair cells of mouse cochlear cultures. J Physiol 474:75-86. CrossRef Medline

Smith KE, Browne L, Selwood DL, McAlpine D, Jagger DJ (2015) Phosphoinositide modulation of heteromeric Kv1 channels adjusts output of spiral 
ganglion neurons from hearing mice. J Neurosci 35:11221-11232. CrossRef Medline

Stepanyan R, Frolenkov GI (2009) Fast adaptation and $\mathrm{Ca}^{2+}$ sensitivity of the mechanotransducer require myosin-XVa in inner but not outer cochlear hair cells. J Neurosci 29:4023-4034. CrossRef Medline

Suh BC, Hille B (2008) PIP $_{2}$ is a necessary cofactor for ion channel function: how and why? Annu Rev Biophys 37:175-195. CrossRef Medline

Tachibana M, Morioka H, Machino M, Oshima W, Mizukoshi F, Mizukoshi O, Yoshioka T (1984) Localization of triphosphoinositide in the cochlea. An electronmicroscopic immunocytochemical study. Histochemistry 81:157-160. CrossRef Medline

Tang QY, Zhang Z, Meng XY, Cui M, Logothetis DE (2014) Structural determinants of phosphatidylinositol 4,5-bisphosphate $\left(\mathrm{PIP}_{2}\right)$ regulation of BK channel activity through the RCK1 Ca2 + coordination site. J Biol Chem 289:18860-18872. CrossRef Medline

Waguespack J, Salles FT, Kachar B, Ricci AJ (2007) Stepwise morphological and functional maturation of mechanotransduction in rat outer hair cells. J Neurosci 27:13890-13902. CrossRef Medline

Webb RJ, East JM, Sharma RP, Lee AG (1998) Hydrophobic mismatch and the incorporation of peptides into lipid bilayers: a possible mechanism for retention in the Golgi. Biochemistry 37:673-679. CrossRef Medline

Xiong W, Grillet N, Elledge HM, Wagner TF, Zhao B, Johnson KR, Kazmierc- zak P, Müller U (2012) TMHS is an integral component of the mechanotransduction machinery of cochlear hair cells. Cell 151:1283-1295. CrossRef Medline

Yang C, Zhang X, Guo Y, Meng F, Sachs F, Guo J (2015) Mechanical dynamics in live cells and fluorescence-based force/tension sensors. Biochim Biophys Acta 1853:1889-1904. CrossRef Medline

Yang JJ, Su MC, Chien KH, Hsin CH, Li SY (2010) Identification of novel variants in the TMIE gene of patients with nonsyndromic hearing loss. Int J Pediatr Otorhinolaryngol 74:489-493. CrossRef Medline

Zaydman MA, Cui J (2014) PIP 2 regulation of KCNQ channels: biophysical and molecular mechanisms for lipid modulation of voltage-dependent gating. Front Physiol 5:195. CrossRef Medline

Zhang Q, Zhou P, Chen Z, Li M, Jiang H, Gao Z, Yang H (2013) Dynamic $\mathrm{PIP}_{2}$ interactions with voltage sensor elements contribute to KCNQ2 channel gating. Proc Natl Acad Sci U S A 110:20093-20098. CrossRef Medline

Zhao B, Wu Z, Grillet N, Yan L, Xiong W, Harkins-Perry S, Müller U (2014) TMIE is an essential component of the mechanotransduction machinery of cochlear hair cells. Neuron 84:954-967. CrossRef Medline

Zhao H, Williams DE, Shin JB, Brügger B, Gillespie PG (2012) Large membrane domains in hair bundles specify spatially constricted radixin activation. J Neurosci 32:4600-4609. CrossRef Medline 